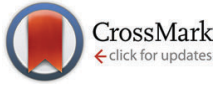

Cite this: Phys. Chem. Chem. Phys., 2014, 16, 25583

Received 18th August 2014, Accepted 16th October 2014

DOI: $10.1039 / c 4 c p 03704 a$

www.rsc.org/pccp

\section{The model case of an oxygen storage catalyst - non-stoichiometry, point defects and electrical conductivity of single crystalline $\mathrm{CeO}_{2}-\mathrm{ZrO}_{2}-\mathrm{Y}_{2} \mathrm{O}_{3}$ solid solutions}

\author{
Jens-Peter Eufinger, ${ }^{a}$ Maximilian Daniels, ${ }^{b}$ Kerstin Schmale, ${ }^{b}$ Stefan Berendts, ${ }^{c}$ \\ Gregor Ulbrich, ${ }^{c}$ Martin Lerch, ${ }^{c}$ Hans-Dieter Wiemhöfer ${ }^{\mathrm{b}}$ and Jürgen Janek ${ }^{\star a}$
}

\begin{abstract}
The ternary solid solution $\mathrm{CeO}_{2}-\mathrm{ZrO}_{2}$ is known for its superior performance as an oxygen storage catalyst in exhaust gas catalysis (e.g. TWC), although the defect chemical background of these outstanding properties is not fully understood quantitatively. Here, a comprehensive experimental study is reported regarding defects and defect-related transport properties of cubic stabilized single crystalline $\left(\mathrm{Ce}_{x} \mathrm{Zr}_{1-x}\right)_{0.8} \mathrm{Y}_{0.2} \mathrm{O}_{1.9-\delta}$ $(0 \leq x \leq 1)$ solid solutions as a model system for $\mathrm{CeO}_{2}-\mathrm{ZrO}_{2}$. The constant fraction of yttria was chosen in order to fix a defined concentration of oxygen vacancies and to stabilize the cubic fluorite-type lattice for all $\mathrm{Ce} / \mathrm{Zr}$ ratios. Measurements of the total electrical conductivity, the partial electronic conductivity, the ionic transference number and the non-stoichiometry (oxygen deficiency, oxygen storage capacity) were performed in the oxygen partial pressure range $-25<\lg p \mathrm{O}_{2} /$ bar $<0$ and for temperatures between $500{ }^{\circ} \mathrm{C}$ and $750{ }^{\circ} \mathrm{C}$. The total conductivity at low $\mathrm{pO}_{2}$ is dominated by electronic transport. A strong deviation from the widely accepted ideal solution based point defect model was observed. An extended point defect model was developed using defect activities rather than concentrations in order to describe the point defect reactions in $\mathrm{CeO}_{2}-\mathrm{ZrO}_{2}-\mathrm{Y}_{2} \mathrm{O}_{3}$ properly. It served to obtain good quantitative agreement with the measured data. By a combination of values for non-stoichiometries and for electronic conductivities, the electron mobility could be calculated as a function of $\mathrm{pO}_{2}$, ranging between $10^{-2} \mathrm{~cm}^{2} \mathrm{~V}^{-1} \mathrm{~s}^{-1}$ and $10^{-5} \mathrm{~cm}^{2} \mathrm{~V}^{-1} \mathrm{~s}^{-1}$. Finally, the origin of the high oxygen storage capacity and superior catalytic promotion performance at a specific ratio of $n(\mathrm{Ce}) / n(\mathrm{Zr}) \approx 1$ was attributed to two main factors: (1) a strongly enhanced electronic conductivity in the high and medium $\mathrm{pO}_{2}$ range qualifies the material to be a good mixed conductor, which is essential for a fast oxygen exchange and (2) the equilibrium constant for the reduction exhibits a maximum, which means that the reduction is thermodynamically most favoured just at this composition.
\end{abstract}

\section{Introduction}

Solid solutions of ceria $\left(\mathrm{CeO}_{2}\right)$ doped with rare earth elements (e.g. $\mathrm{Gd}, \mathrm{Y}, \mathrm{Sm})$ are known for their excellent performance as high temperature oxygen electrolytes. The ceria host lattice with cubic fluorite-type structure accepts high concentrations of aliovalent cations in the cerium sublattice. Substitution of cerium by trivalent metal ions (e.g. $\left.\mathrm{Gd}^{3+}\right)$ leads to the formation of oxygen vacancies and results in highly increased oxygen ion conductivity, which is superior even to that of YSZ (yttria-stabilized zirconia).

\footnotetext{
${ }^{a}$ Physikalisch-Chemisches Institut, Justus-Liebig-University Gießen, Heinrich-Buff-Ring 58, 35392 Gießen, Germany.

E-mail: juergen.janek@phys.chemie.uni-giessen.de

${ }^{b}$ Westfälische Wilhelms-Universität Münster, Institut für Anorganische und Analytische Chemie, Corrensstraße 28/30, 48149 Münster, Germany

${ }^{c}$ Institut für Chemie, TU Berlin, Straße des 17. Juni 135, 10623 Berlin, Germany
}

Different from zirconium, cerium is easily reduced from $\mathrm{Ce}^{4+}$ to $\mathrm{Ce}^{3+}$, and thus, ceria solid solutions are typical mixed electronic and ionic conductors (MIECs) at reduced oxygen partial pressures depending on the actual composition.

First detailed investigations of the conductivity and defect chemistry of pure ceria have been performed in the $1970 \mathrm{~s}^{1-3} \mathrm{CeO}_{2}$ was classified as an n-type semiconductor and the electronic transport mechanism was described as polaron hopping, due to comparably small electron mobilities in the order of $\mu_{\mathrm{e}}=10^{-3} \mathrm{~cm}^{2} \mathrm{~V}^{-1} \mathrm{~s}^{-1}$ at $1000{ }^{\circ} \mathrm{C}^{4}$ (see Section 2). In some early studies ceria was considered to show metal excess $\left(\mathrm{Ce}_{1+y} \mathrm{O}_{2}\right)$ due to cerium interstitials, ${ }^{2,5}$ but in general ceria was supposed to be oxygen deficient $\left(\mathrm{CeO}_{2-x}\right)^{3,6}$ with oxygen vacancies as major ionic point defect. In numerous theoretical and experimental studies this defect model was generally confirmed and is now well understood, ${ }^{7-10}$ making ceria one of the mixed-conducting model cases in solid state ionics. 
Due to their wide range of homogeneity, solid solutions of ceria with other oxides play a role either as electrolytes in intermediate temperature solid oxide fuel cells, ${ }^{11-13}$ as mixed conductors in very stable oxygen permeation membranes, ${ }^{14}$ as conducting or catalytically active components in oxygen sensors and as oxygen storage additives and catalysts in heterogeneous catalysis. In current three way catalytic converters for automotive applications, $\mathrm{Pt} /(\mathrm{Ce}, \mathrm{Zr}) \mathrm{O}_{2}$ composites are widely used as active materials. ${ }^{15,16} \mathrm{CeO}_{2}$ can reversibly release and store oxygen under varying reducing and oxidizing conditions, and $\mathrm{ZrO}_{2}$ stabilizes the crystalline lattice, but also enhances the oxygen storage ability. Harmful exhaust gases (CO, $\mathrm{NO}_{x}$, hydrocarbons) are oxidized to $\mathrm{CO}_{2}$ and $\mathrm{H}_{2} \mathrm{O}$ or reduced to $\mathrm{N}_{2}$ on the Pt catalyst at which the $\mathrm{CeO}_{2}$ containing solid solution buffers an optimum of the local oxygen activity.

A measure for the ability to release and store oxygen is usually given by the oxygen storage capacity (OSC $\left[\mathrm{mol} \mathrm{O}_{2} \mathrm{~g}^{-1}\right]$ ). The OSC, as a practical quantity used in catalyst research, is directly related to the available range of non-stoichiometry $\delta$ corresponding to a single phase material with the formula $\mathrm{CeO}_{2-\delta}$. The highest OSC and the best catalytic performance was found at compositions with a metal ratio of $n(\mathrm{Ce}) / n(\mathrm{Zr}) \approx 1$, i.e. for $\mathrm{Ce}_{0.5} \mathrm{Zr}_{0.5} \mathrm{O}_{2} \cdot{ }^{17-20}$ In theoretical calculations the oxygen vacancy formation energy turns out to show a minimum at this ratio. ${ }^{21-23}$ As well shown by Chiodelli et al., ${ }^{24}$ Lee et al. ${ }^{25}$ and Kuhn et al., ${ }^{26}$ defect chemical modelling is essential for the fundamental understanding of the OSC and for further improvement.

The solid solution system $\mathrm{CeO}_{2}-\mathrm{ZrO}_{2}-\mathrm{Y}_{2} \mathrm{O}_{3}$ has already been examined in polycrystalline form with regard to total conductivity, ${ }^{25,27-33}$ partial electronic conductivity ${ }^{34}$ and nonstoichiometry $^{26,35}$ as a function of temperature and oxygen partial pressure. Reviewing these studies, three questions remain open: (a) it was observed by Cales and Baumard, ${ }^{31}$ Lee et $a l .{ }^{32}$ and Xiong et $a l .{ }^{34}$ that the course of the total and the partial electronic conductivity as a function of oxygen partial pressure deviates strongly from the "classical" point defect model for acceptor doping (see Section 2), especially at low $\mathrm{pO}_{2}$. A slope of $-1 / 6$ is expected in the $\lg \sigma v s . \lg p \mathrm{O}_{2}$ graph, but the conductivity flattens at low $\mathrm{pO}_{2}$ and for some compositions and temperatures even exposes a maximum with decreasing $\mathrm{pO}_{2}$. The authors proposed a change in the electron mobility to be responsible for this observation but a quantitative proof was not yet provided. (b) The non-stoichiometry $\delta$ of the systems $\mathrm{CeO}_{2}, \mathrm{Ce}-\mathrm{Zr}-\mathrm{O}$ and $\mathrm{Ce}-\mathrm{Zr}-\mathrm{Y}-\mathrm{O}$ was measured isothermally as a function of $\mathrm{pO}_{2}$ in the temperature range between $700 \leq \theta /{ }^{\circ} \mathrm{C} \leq$ 1500 by Panlener et al., ${ }^{6}$ Kuhn et $a .^{26}$ and Otake et al. ${ }^{35}$ In particular at low temperatures the reduction of cerium appears to be hindered, and a much smaller non-stoichiometry than expected is observed. ${ }^{3}$ With decreasing $p \mathrm{O}_{2}, \delta$ even attains a plateau. The currently accepted ideal point defect model, which predicts a continuous increase of $\delta$ up to the full reduction of $\mathrm{Ce}^{4+}$ to $\mathrm{Ce}^{3+}$, cannot explain this behaviour. (c) It is well known that grain boundaries in ceria-based ceramic materials show different defect chemistry as compared to the bulk. ${ }^{36-38}$ Therefore, it is also an implicit aim of the present study to determine a collection of essential transport properties for single crystals as reference data, in order to judge the role of grain boundaries in studies of polycrystalline material and to get a basic overview of pure bulk properties.

In the present work we try to address these questions by performing a comprehensive defect-chemical analysis of single crystalline $\left(\mathrm{Ce}_{x} \mathrm{Zr}_{1-x}\right)_{0.8} \mathrm{Y}_{0.2} \mathrm{O}_{1.9-\delta}(0 \leq x \leq 1)$ solid solutions in a wide range of composition. The fixed content of $\mathrm{Y}$ is used to retain the cubic phase even at low cerium concentration. Otherwise, at low Ce concentration, the system would transform into the tetragonal phase. Single crystals were prepared by the skull-melting method, and we determined the total electric conductivity, the oxygen ion transference number, the partial electronic conductivity and the non-stoichiometry as a function of $\mathrm{pO}_{2}$ and $T$. The use of single crystals instead of ceramic samples, as in previous work, ${ }^{39,40}$ opens up the chance to investigate exclusively the bulk properties without an interference from grain boundaries. The obtained data may therefore serve as reference data.

\section{Point defect model of $\mathrm{CeO}_{2}-\mathrm{ZrO}_{2}-$ $\mathrm{Y}_{2} \mathrm{O}_{3}$ solid solutions}

Acceptor doping of ceria or zirconia can be understood as dissolution of lower valent metal oxides (e.g. $\mathrm{Y}_{2} \mathrm{O}_{3}, \mathrm{Gd}_{2} \mathrm{O}_{3}$ ) in the $\mathrm{MO}_{2}$ host lattice where the metal takes the redox state $\mathrm{M}^{4+}$ $(\mathrm{M}=\mathrm{Ce}, \mathrm{Zr})$. The introduction of $\mathrm{Y}_{2} \mathrm{O}_{3}$ by substitution is described by the following equation in the Kröger-Vink notation:

$$
\mathrm{Y}_{2} \mathrm{O}_{3}+2 \mathrm{M}_{\mathrm{M}}^{\times}+\mathrm{O}_{\mathrm{O}}^{\times} \rightarrow 2 \mathrm{Y}_{\mathrm{M}}^{\prime}+\mathrm{V}_{\mathrm{O}}^{\bullet \bullet}+2 \mathrm{MO}_{2}
$$

To conserve charge neutrality, the incorporation of $\mathrm{Y}^{3+}$ on $\mathrm{Ce}^{4+}$ or $\mathrm{Zr}^{4+}$ sites is compensated by the formation of oxygen vacancies, i.e. in other words one gets a solid solution of two compounds in the fluorite-type structure with compositions $\mathrm{YO}_{1.5}-0.5$ and $\mathrm{MO}_{2}$. Therefore, in the medium oxygen partial pressure range once the loss of oxygen due to reduction of $\mathrm{M}^{4+}$ is still small - the concentration of oxygen vacancies is fixed by the concentration of $\mathrm{Y}$ as $2\left[\mathrm{~V}_{\mathrm{O}}^{\bullet \bullet}\right]=\left[\mathrm{Y}_{\mathrm{M}}^{\prime}\right]$ (Fig. 1, region II). Entering the low $p \mathrm{O}_{2}$ range upon decreasing oxygen partial pressure, $\mathrm{Ce}^{4+}$ is reduced to $\mathrm{Ce}^{3+}$ while more oxygen vacancies and electrons are formed (we assume that electrons are localized as polarons on $\mathrm{Ce}^{3+}$ sites, $\left.\left[\mathrm{Ce}_{\mathrm{Ce}}^{\prime}\right]=\left[\mathrm{e}^{\prime}\right]\right)$,

$$
\begin{gathered}
2 \mathrm{Ce}_{\mathrm{Ce}}^{\times}+\mathrm{O}_{\mathrm{O}}^{\times} \rightleftharpoons 2 \mathrm{Ce}_{\mathrm{Ce}}^{\prime}+\mathrm{V}_{\mathrm{O}}^{\bullet \bullet}+1 / 2 \mathrm{O}_{2} \\
K_{1}=\frac{\left[\mathrm{Ce}_{\mathrm{Ce}}^{\prime}\right]^{2}\left[\mathrm{~V}_{\mathrm{O}}^{\bullet \bullet}\right] p_{\mathrm{O}_{2}}^{1 / 2}}{\left[\mathrm{Ce}_{\mathrm{Ce}}^{\times}\right]^{2}\left[\mathrm{O}_{\mathrm{O}}^{\times}\right]}
\end{gathered}
$$

where $[D]$ denotes the concentration of the respective defect species and regular structure elements per formula unit and $K_{1}$ the equilibrium constant. In region II, where the condition $2\left[\mathrm{~V}_{\mathrm{O}}^{\bullet \bullet}\right]=\left[\mathrm{Y}_{\mathrm{M}}^{\prime}\right]$ is still valid and with the assumption of $\left[\mathrm{Ce}_{\mathrm{Ce}}^{\times}\right]$, $\left[\mathrm{O}_{\mathrm{O}}^{\times}\right]=$const., eqn (3) can be simplified, leading to a proportionality of $\left[\mathrm{Ce}_{\mathrm{Ce}}^{\prime}\right] \propto p_{\mathrm{O}_{2}}^{-1 / 4}$, i.e. the electron concentration increases with decreasing $p \mathrm{O}_{2}$ in a well-defined dependence. 


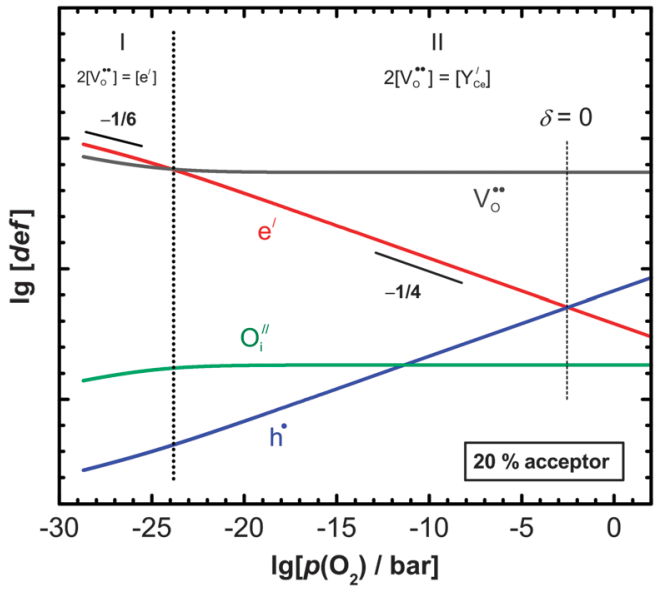

Fig. 1 Schematic Brower diagram of 20\% acceptor-doped ceria (e.g. Y, $\mathrm{Gd}, \mathrm{Sm})$. Roman numbers and dotted lines mark regions with different majority defect pairs (refer to the text). Region II corresponds to the extended plateau of constant ionic charge carrier concentration caused by acceptor compensation. The stoichiometric point is marked with the line at $\delta=0$.

At lower oxygen partial pressures the loss of oxygen leads to the formation of more vacancies than brought in by yttrium, and the electroneutrality condition reads now $\left[\mathrm{Ce}_{\mathrm{Ce}}^{\prime}\right]=2\left[\mathrm{~V}_{\mathrm{O}}^{\bullet \bullet}\right]$, i.e. the electron concentration $\left[\mathrm{Ce}_{\mathrm{Ce}}^{\prime}\right]$ is now fixed by the oxygen vacancy concentration. A different proportionality of $\left[\mathrm{Ce}_{\mathrm{Ce}}^{\prime}\right]=$ $2\left[\mathrm{~V}_{\mathrm{O}}^{\bullet \bullet}\right] \propto p_{\mathrm{O}_{2}}^{-1 / 6}$ (Fig. 1, region $\mathrm{I}$ ) is obtained, and the increase in electron concentration with decreasing $p \mathrm{O}_{2}$ shows a smaller slope than in range II.

The electronic charge transport takes place via activated hopping of electrons between cerium ions as concluded by Tuller et al. from the low mobility of electrons in ceria ${ }^{4}$ (small polaron mechanism). The total electrical conductivity $\sigma$, which is the sum of all partial conductivities, is then given as

$$
\sigma=e_{0} \cdot \mu_{\mathrm{e}} \cdot \beta \cdot\left[\mathrm{Ce}_{\mathrm{Ce}}^{\prime}\right]+2 e_{0} \cdot \mu_{\mathrm{v}} \cdot \beta \cdot\left[\mathrm{V}_{\mathrm{O}}^{\bullet \bullet}\right],
$$

where $e_{0}$ denotes the elementary charge, $\mu_{\mathrm{e}}$ and $\mu_{\mathrm{v}}$ represent the mobilities of electrons and oxygen vacancies, respectively, and $\beta \equiv \frac{N_{\mathrm{A}}}{V_{\mathrm{m}}}$ the number density (number of formula units per $\mathrm{cm}^{3}$, with $N_{\mathrm{A}}$ and $V_{\mathrm{m}}$ as Avogadro's constant and molar volume).

It has to be noted that according to Fig. 1 on the right of region II p-type conductivity occurs instead of n-type conductivity.
Due to significant concentration of $\mathrm{Ce}^{3+}$, n-type conductivity (electronic) predominates on the left in the medium and low oxygen partial pressure range. However, p-type conductivity in the yttria doped ceria-zirconia solid solutions was only visible in a small range at relatively high oxygen partial pressure. Thus, it is less accessible in the relevant oxygen pressure range than, for instance, reported for gadolinia doped ceria ${ }^{48}$ and following discussion omits data for the p-type conductivity.

\section{Experimental}

\subsection{Single crystal preparation}

Single crystals of $\left(\mathrm{Ce}_{x} \mathrm{Zr}_{1-x}\right)_{0.8} \mathrm{Y}_{0.2} \mathrm{O}_{1.9-\delta}(0 \leq x \leq 1)$ were prepared using the skull-melting technique. ${ }^{41}$ Before melting, the powder binary oxides were carefully mixed in the respective ratios $\left(\mathrm{ZrO}_{2} 99.91 \%\right.$ purity, $\mathrm{Y}_{2} \mathrm{O}_{3} 99.991 \%$ purity, Surface Net, Rheine, Germany, $\mathrm{CeO}_{2}$ 99.9\% purity, Chempur, Karlsruhe, Germany, ignition material: Zr 99.6\% purity, Haines \& Maassen, Bonn, Germany). Skull-melting is an outstanding method for the growth of very pure single crystals with, in theory, no limitation concerning the melting temperature. It can be described as a quasi crucible-free high frequency (HF) process where the material is included in a water-cooled crucible. Power transfer occurs via a HF-field. By addition of a small amount of ignition metal $(\mathrm{Zr})$ to the oxide material, it can be coupled to the HF-field and heated up to its melting point. Between the molten material and the cool crucible a thin ceramic layer (the skull) remains, protecting the melt from impurities. After the whole interior becomes molten, the crucible is slowly moved out of the HF-field and crystals grow in a Bridgman-like process from the bottom of the skull. After undergoing the process, single crystals with typical dimensions of around $6 \times 6 \times 15 \mathrm{~mm}^{3}$ were obtained (Fig. 2).

\subsection{Structural characterisation}

The chemical composition of the solid solutions was determined via wavelength-dispersive X-ray spectroscopy (WDS) with an electron beam micro probe (Cameca Camebax Microbeam, Gennevilliers, France). X-ray diffraction was performed to identify the crystallographic phases. For this purpose the single crystals were ground in a mortar and the powders were investigated using a Siemens D5000 diffractometer in common Bragg-Brentano $\theta-2 \theta$ geometry with $\mathrm{Cu} \mathrm{K}_{\alpha 1}$ radiation. Hereby, a $\mathrm{Ge}(111)$ single crystal was used as a primary monochromator for better signal quality. Step width was kept at $2 \theta=0.019$ with a step

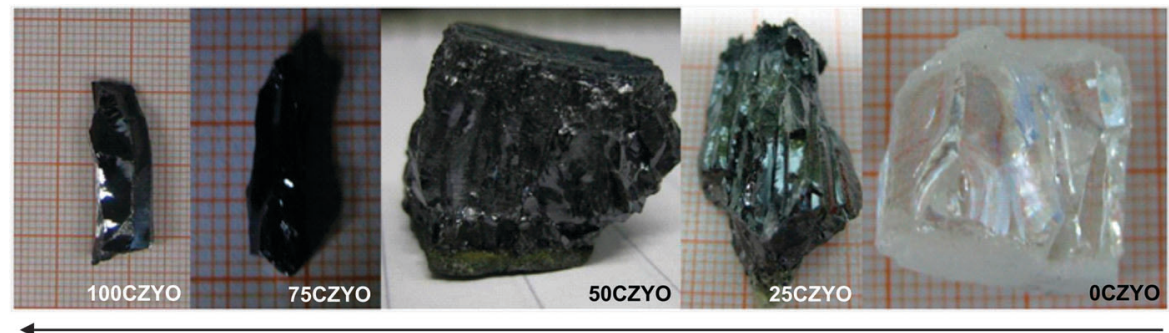

$x$ (ceria content)

Fig. 2 Single crystals of $\left(\mathrm{Ce}_{x} \mathrm{Zr}{ }_{1-x}\right)_{0.8} \mathrm{Y}_{0.2} \mathrm{O}_{1.9-\delta}(0 \leq x \leq 1)$ with different composition prepared by the skull-melting technique (as-received). 
time of 30-84 s. Rietveld refinements were carried out with the program package FullProf. ${ }^{42}$

To study the vibrational structure and the transition from ceria-rich to zirconia-rich compositions Raman spectroscopy was carried out using a Bruker SENTERRA Raman Microscope (Bruker Optics GmbH, Ettlingen, Germany) equipped with a $532 \mathrm{~nm}$ Laser source at a power rate of $10-20 \mathrm{~mW}$. High temperature during the growth process resulted in strong reduction and therefore in a high degree of non-stoichiometry in the obtained single crystals. Prior to the measurement, small single crystal pieces of each composition were therefore annealed in air at $800{ }^{\circ} \mathrm{C}$ for $5 \mathrm{~h}$ to re-oxidize the samples and to get close to the stoichiometric point.

\subsection{Total electrical conductivity as a function of $T$ and $\mathrm{pO}_{2}$}

The total electrical conductivity was measured via electrochemical impedance spectroscopy (EIS) inside a gas-tight high temperature tube furnace with shielded platinum wires in the temperature range of $250 \leq \theta /{ }^{\circ} \mathrm{C} \leq 800$. The obtained crystals with a volume of about $0.1 \mathrm{~cm}^{3}$ were cut into rectangular bars of approx. $1 \times 1 \times 5 \mathrm{~mm}^{3}$. The exact dimensions of the crystals were measured with a digital calliper. To ensure good electrical contact silver conducting paste (Ag conducting silver 200, Ferro $\mathrm{GmbH}$, Hanau, Germany) was painted on both small faces of the bars leading to a maximized electrode distance and therefore to a maximized cell constant. The silver paste was dried at ambient temperature and atmosphere.

Due to the high nucleation rates during the skull-melting process the preparation of large single crystals was sometimes difficult. Therefore, some of the bars, especially those with high ceria content, consisted of two or three crystallites. However, the contribution of one or two grain boundaries is negligible (see Section 4.2). The sample bars were fixed within a spring loaded holder made of alumina tubes and two parallel silver plates as electrodes. The sample temperature was measured using a type $\mathrm{S}$ thermocouple with an experimental error of $\pm 1{ }^{\circ} \mathrm{C}$. The oxygen partial pressure in the flowing gas atmosphere was controlled by mixtures of $\mathrm{CO} / \mathrm{CO}_{2}, \mathrm{H}_{2} / \mathrm{H}_{2} \mathrm{O}$ and $\mathrm{Ar} / \mathrm{O}_{2}$ in the range of $-30<\lg \left[p\left(\mathrm{O}_{2}\right) / \mathrm{bar}\right] \leq 0$. To monitor the oxygen partial pressure, a self-made zirconia based oxygen sensor was placed downstream. One side of the sensor was exposed to air.

Electrochemical impedance spectroscopy (EIS) in twoterminal configuration was performed using an EG\&G potentiostat (Model 283) linked with a Princeton Applied Research frequency response detector (Model 1025) operating at a frequency range between $500 \mathrm{kHz}$ and $100 \mathrm{mHz}$ at a voltage amplitude of $20 \mathrm{mV}$ RMS. At each $T$ and $p\left(\mathrm{O}_{2}\right)$ step the sample was allowed to equilibrate for 3-10 $\mathrm{h}$ before the measurement was started. The impedance spectra were evaluated with the program PowerSine (provided by the manufacturer of the measurement system, Princeton Applied Research). The total electrical conductivity of the sample crystals was then calculated according to $\sigma=l /(A \cdot R)$ where $\sigma$ denotes the total conductivity, $l$ the electrode distance (sample length), $A$ the sample cross section and $R$ the evaluated resistance from the impedance data.

\subsection{Principles and the procedure of EMF measurement}

The ionic transference number of our samples was measured in a galvanic concentration cell. ${ }^{43,44} \mathrm{~A}$ piece of electrolyte is exposed like a membrane to a chemical potential gradient of oxygen while measuring the electrical potential difference of two (inert) platinum electrodes, fixed at opposite sides of the electrolyte. The oxygen redox equilibrium of the solid/gas interfaces creates an open cell voltage (EMF, electromotive force) across the $\operatorname{Pt}^{\mathrm{I}}\left(\mathrm{O}_{2}\right)|\mathrm{MIEC}| \mathrm{Pt}^{\mathrm{II}}\left(\mathrm{O}_{2}\right)$ cell. The resulting voltage $(E)$ is given by Wagner's transport theory ${ }^{45,46}$ as

$$
E=-\frac{1}{4 F} \int_{\mu_{\mathrm{O}_{2}}^{\mathrm{I}}}^{\mu_{\mathrm{O}_{2}}^{\mathrm{II}}} t_{\mathrm{O}^{2-}} \mathrm{d} \mu_{\mathrm{O}_{2}},
$$

where $\mu_{\mathrm{O}_{2}}^{\mathrm{I}}$ and $\mu_{\mathrm{O}_{2}}^{\mathrm{II}}$ represent the chemical potentials of oxygen on each side of the electrolyte cell, $t_{\mathrm{O}^{2-}}$ the transference number of oxygen ions and $F$ the Faraday constant. Eqn (5) can then be integrated to eqn (6), if the chemical potential difference of oxygen is kept small (less than one order of magnitude), and therefore the transference number $t_{\mathrm{O}^{2-}}$ can be considered as a constant within this potential difference.

$$
E=-\bar{t}_{\mathrm{O}^{2-}} \cdot \frac{R T}{4 F} \ln \frac{p_{\mathrm{O}_{2}}^{\mathrm{II}}}{p_{\mathrm{O}_{2}}^{\mathrm{I}}}
$$

In fact, $E$ is a direct measure of the transference number of oxygen ions in a well-defined concentration cell. During the experiment, the measured cell voltage $E$ is compared to the voltage $E_{\text {ref }}$ of a reference oxygen sensor with $t_{\mathrm{O}^{2-} \text {,ref }} \approx 1$. From mathematical division according to

$$
t_{\mathrm{O}^{2-}} \approx \bar{t}_{\mathrm{O}^{2-}}=\frac{E}{E_{\mathrm{ref}}},
$$

the mean oxygen ion transference number $\bar{t}_{\mathrm{O}^{2-}}$ for the specific partial pressure range results. Additional information, a description of the experimental setup and of the sample preparation can be found in a previous report. ${ }^{47}$

The disc shaped samples (O.D. $10 \mathrm{~mm}$, thickness $1.5 \mathrm{~mm}$, sealing: one gold ring of $10 \mathrm{~mm}$ O.D.) were first equilibrated at a constant temperature of $700{ }^{\circ} \mathrm{C}$ in air. Afterwards, both oxygen partial pressures $p \mathrm{O}_{2}^{\mathrm{I}}$ and $p \mathrm{O}_{2}^{\mathrm{II}}$ were changed stepwise in a range of $-23<\lg \left(p \mathrm{O}_{2} /\right.$ bar $) \leq 0$ so that their difference was approx. one order of magnitude $\left(\Delta \lg \left(p \mathrm{O}_{2} /\right.\right.$ bar $\left.) \approx 1\right)$. The sample was allowed to equilibrate under the new conditions until cell voltage and reference voltage were stable, before the next step was adjusted. Finally, the transference number of oxygen ions was plotted against a logarithmic mean oxygen partial pressure $p_{\mathrm{O}_{2}}$ defined by

$$
\lg \left[p_{\mathrm{O}_{2}}\right]=\frac{\lg \left[p_{\mathrm{O}_{2}}^{\mathrm{I}}\right]+\lg \left[p_{\mathrm{O}_{2}}^{\mathrm{II}}\right]}{2}
$$

\subsection{Hebb-Wagner polarization technique}

Hebb-Wagner measurements present a special type of direct current measurements used for the determination of minority carrier conductivities as a function of a variable thermodynamic activity. ${ }^{46,48,49}$ The basic feature to measure a minority electron 
conductivity consists of the use of a two or three probe cell with an ion blocking working electrode, the potential of which is controlled versus a reference electrode with fixed thermodynamic activity. In the present case, the experimental setup was equipped with an oxygen ion blocking micro contact made of a Pt wire, which was pressed onto the sample. Its surrounding was encapsulated with a glass layer to prevent any exchange of gaseous oxygen and thus any steady state flux of the majority charge carrier (oxygen ions). This allows us to measure a small electronic conductivity in acceptor doped ceria-zirconia in spite of the predominant ionic conduction, i.e. $\sigma_{\text {ion }} \gg \sigma_{\mathrm{e}} .{ }^{50,51}$

Hence, the boundary condition at the Pt micro contact corresponds to a vanishing partial oxygen ion current $i_{\mathrm{O}^{2-}}$ at $r=a$, if considered as a hemispherical contact surface with radius $a$,

$$
i_{\mathrm{O}^{2-}}=0(\text { at } r=a) \text {. }
$$

The oxygen ion charge flux is the sum of a concentration gradient driven chemical diffusion term and a migration term driven by an electric potential gradient according to

$$
i_{\mathrm{O}^{2-}}=\frac{\sigma_{\mathrm{O}^{2-}} \cdot \sigma_{\mathrm{e}}}{\sigma_{\mathrm{O}^{2-}}+\sigma_{\mathrm{e}}} \cdot \frac{1}{2 F} \cdot \operatorname{grad} \mu_{\mathrm{O}}+\frac{\sigma_{\mathrm{O}^{2-}}}{\sigma_{\mathrm{O}^{2-}}+\sigma_{\mathrm{e}}} \cdot i_{\text {tot }},
$$

where $\sigma_{\mathrm{O}^{2-}}$ and $\sigma_{\mathrm{e}}$ denote the oxygen ion and the electron conductivity, respectively, as well as $i_{\text {tot }}$ the total electrical current density, $F$ Faraday's constant, and $\mu_{\mathrm{O}}$ the chemical potential of oxygen. Substituting the expression (10) for the partial ionic charge flux in the boundary condition (9) of the blocking Pt electrode yields the following simple equation for the total electrical current density $i_{\text {tot: }}$ :

$$
i_{\text {tot }}=-\frac{\sigma_{\mathrm{e}}}{2 F} \cdot \operatorname{grad} \mu_{\mathrm{O}}=-\frac{\sigma_{\mathrm{e}}}{2 F} \cdot \frac{\mathrm{d} \mu_{\mathrm{O}}}{\mathrm{d} r}
$$

For the steady state, the vanishing of the oxygen ion current extends to the entire sample between the two electrodes. Hence, eqn (11) is valid throughout the sample. Assuming a hemispherical symmetry of the contact surface and of the current lines with a very small contact radius $a$ as compared to the distance $L$ between microcontact and counter electrode, the steady state electrical current density around the microcontact can be taken as

$$
i_{\text {tot }}(r)=\frac{I}{2 \pi r^{2}}
$$

where $I$ denotes the total electric current measured in the cell. The hemispherical symmetry with the radial dependence $1 / r^{2}$ is usually a very good approximation for $a \ll L^{49}$ Under this condition, the current densities far from the microcontact are negligibly small. Then it is a fairly good approximation to replace the position of the counter electrode by the limiting value $L \rightarrow \infty$. Accordingly, integration of eqn (11) between the electrode positions $r=a$ and $r=\infty$ on the left and on the right with respect to the chemical potentials at both electrodes yields for the steady state electrical current

$$
\frac{2 F I}{2 \pi} \cdot \int_{a}^{\infty} \frac{1}{2 r^{2}} \mathrm{~d} r=\frac{F}{2 \pi a} I=-\int_{\mu_{\mathrm{O}}^{\text {micr }}}^{\mu_{\mathrm{er}}^{\mathrm{ref}}} \sigma_{\mathrm{e}} \mathrm{d} \mu_{\mathrm{O}} .
$$

In order to obtain the steady state current-voltage relation, one has to make use of the steady state cell voltage as a function of chemical potential of oxygen:

$$
\begin{aligned}
2 F U=\mu_{\mathrm{O}}^{\text {micr }}-\mu_{\mathrm{O}}^{\text {ref }} & =\frac{R T}{2} \ln \left(\frac{p_{\mathrm{O}_{2}}^{\text {micr }}}{p_{\mathrm{O}_{2}}^{\text {ref }}}\right) \rightarrow 2 F \cdot \mathrm{d} U \\
& =\mathrm{d} \mu_{\mathrm{O}}^{\text {micr }} \text { with } \mu_{\mathrm{O}}^{\text {ref }}=\text { const. }
\end{aligned}
$$

As the chemical potential $\mu_{\mathrm{O}}^{\text {ref }}$ at the reference electrode is a constant, a differentiation of the electrical current in eqn (13) with respect to the variable lower bound $\mu_{\mathrm{O}}^{\text {micr }}$ together with the subsequent replacement $\mathrm{d} \mu_{\mathrm{O}}^{\text {micr }}=2 F \mathrm{~d} U$ finally yields the following relation between the electronic conductivity $\sigma_{\mathrm{e}}$, the steady state voltage $U$ and the measured current $I$ :

$$
\sigma_{\mathrm{e}}\left(p_{\mathrm{O}_{2}}^{\text {micr }}\right)=\frac{1}{2 \pi r} \cdot\left(\frac{\mathrm{d} I}{\mathrm{~d} U}\right)_{U}\left(p_{\mathrm{O}_{2}}^{\text {micr }}\right)
$$

Here, $p_{\mathrm{O}_{2}}^{\text {micr }}$ denotes the local oxygen partial pressure at the micro contact caused by the applied voltage $U\left(p_{\mathrm{O}_{2}}^{\text {micr }}\right)$. The experimental cell voltage $U_{\exp }$ usually has to be corrected in the steady state according to

$$
U_{\exp }=\frac{R T}{4 F} \cdot \ln \left(\frac{p_{\mathrm{O}_{2}}^{\text {micr }}}{0.21 \text { bar }}\right)+U_{\text {contact }} .
$$

The additional term $U_{\text {contact }}=R_{\text {contact }} \cdot I$ takes into account an additional ohmic contact resistance $R_{\text {contact }}$ at the microcontact. It can be determined from additional current-pulse measurements or an evaluation of the voltage jump after switching-off from a steady-state polarization by an external voltage. Knowing the steady-state current $I$, the corrected experimental voltage $U$ to be used in eqn (16) is

$$
U=U_{\text {exp }}-R_{\text {contact }} I .
$$

The Hebb-Wagner measurements were performed using a Keithley 2601 sourcemeter. A planar platinum back contact was prepared at the bottom of the disc shaped single crystal sample and a second platinum micro-contact with a diameter of about $300-400 \mu \mathrm{m}$ was placed on the top surface. The platinum microcontact was encapsulated with glass paste (Heraeus 041) to prevent oxygen exchange around the micro contact. The measurements were conducted in the temperature range $500-800{ }^{\circ} \mathrm{C}$.

According to eqn (16), a positive voltage can considerably increase the oxygen partial pressure around the micro contact below the glass paste layer in the steady state. For instance, $+0.1 \mathrm{~V}$ already corresponds to a partial pressure of about two decades higher than the reference (usually air). Hence, applying positive potentials above $0.2 \mathrm{~V}$ and higher sometimes caused the formation of oxygen filled bubbles at the interface between the glass paste and the single crystal. Therefore, we restricted the voltage on the positive polarity to a maximum of $0.1 \mathrm{~V}$, whereas the lowest negative voltages usually amounted to $-0.8 \mathrm{~V}$, in some cases, lower limits down to $-1.5 \mathrm{~V}$ were investigated, too.

\subsection{Coulometric titration}

The non-stoichiometry $\delta$, defined as oxygen deficit in $\left(\mathrm{Ce}_{x} \mathrm{Zr}_{1-x}\right)_{0.8} \mathrm{Y}_{0.2} \mathrm{O}_{1.9-\delta}(0 \leq x \leq 1)$, was determined at $700{ }^{\circ} \mathrm{C}$ 


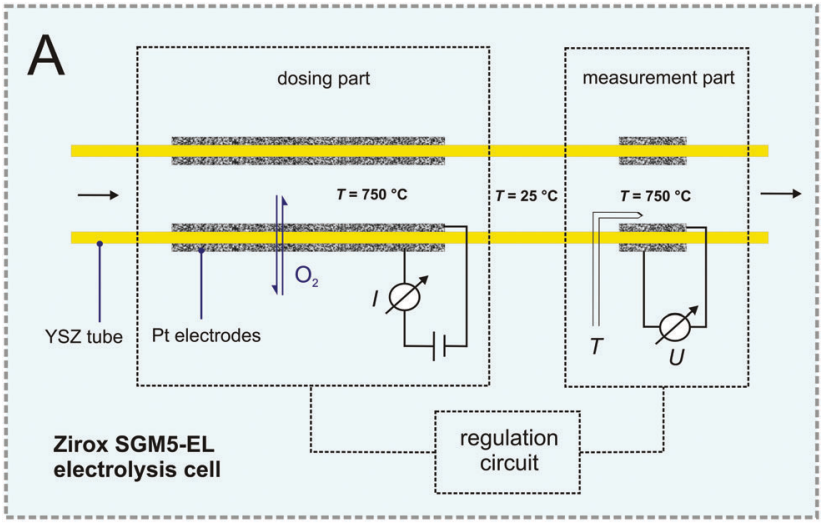

B

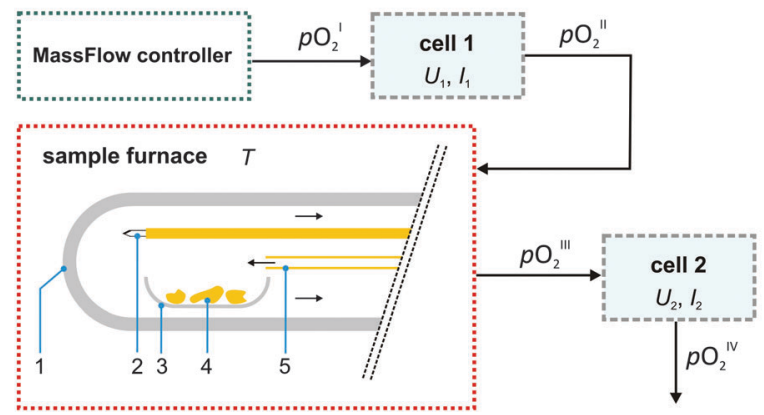

Fig. 3 Experimental setup of the carrier gas coulometric technique: A-electrolysis cell, B-gas flow chart. Data acquisition and control is performed with a PC. Feed gases were premixed in appropriate ratios with mass flow controllers. The sample furnace consists of a semi-closed quartz tube (1) at the closed end inside the furnace the sample crystals (4) were placed into a small quartz crucible (3) and were flushed by the feed gas through an alumina tube (5). The current temperature was monitored using a type $\mathrm{S}$ thermocouple (2). The original experiment was designed by Teske et al. ${ }^{52}$

in the range of $-25<\lg \left[p\left(\mathrm{O}_{2}\right) / \mathrm{bar}\right]<0$ by a carrier gas coulometric titration technique as described by Teske et al. ${ }^{52} \mathrm{~A}$ few single crystals (three to five) of CZYO with the total amount of approx. $250 \mathrm{mg}$ were placed into a quartz crucible inside the experimental setup. The key parts of the arrangement are two zirconia based solid electrolyte cells (SGM5-EL, ZIROX GmbH, Greifswald, Germany), acting both as oxygen pump and oxygen sensor (Fig. 3A). These cells allow a precise control of the oxygen partial pressure $p \mathrm{O}_{2}$ in a gas stream of approx. $50 \mathrm{~cm}^{3} \mathrm{~min}^{-1}$, while measuring the required electrolysis current. A regulation circuit compares the actual cell voltage $U$ with the set point voltage according to the Nernst equation

$$
U=\frac{R T}{4 F} \cdot \ln \left[\frac{p_{\mathrm{O}_{2}}^{\text {in }}}{p_{\mathrm{O}_{2}}^{\text {air }}}\right],
$$

and continuously adjusts the electrolysis current $I$ to reach the pre-set cell voltage. Fig. 3B presents the gas flow chart of the experimental setup. At first, appropriate gas mixtures of $\mathrm{O}_{2} / \mathrm{Ar}$, $\mathrm{CO} / \mathrm{CO}_{2}$ and $\mathrm{Ar} / \mathrm{H}_{2}(95 / 5 \mathrm{vol} \%)-\mathrm{Ar}$, respectively, for the high, medium and low oxygen partial pressure region, were premixed with the aid of mass flow controllers $\left(p \mathrm{O}_{2}^{\mathrm{I}}\right)$. The fine adjustment of the feed gas oxygen partial pressure was done with cell 1 . To get close to the stoichiometric point the sample was first equilibrated in oxygen at $600{ }^{\circ} \mathrm{C}$ for $6 \mathrm{~h}$ and then allowed to cool down. Afterwards, it was flushed with a specific $p \mathrm{O}_{2}^{\text {II }}$ at room temperature. This step is necessary, since at room temperature no oxygen exchange will occur. Meanwhile, cell 2, which was set to a higher $p \mathrm{O}_{2}$, continuously pumps oxygen into the gas flow. When all $p \mathrm{O}_{2}$ and current signals were stable the sample was then heated up to $700{ }^{\circ} \mathrm{C}$ and started to exchange oxygen with the gas phase until it is in the equilibrium state. This oxygen exchange results in a variation in $p \mathrm{O}_{2}^{\text {III }}$ and therefore in the current signal of cell 2 . The mathematical integration of the peak-shaped $I v$ s. $t$ plot, after the base line correction, results in the molar amount of exchanged oxygen:

$$
n_{\mathrm{O}_{2}}=\frac{1}{4 F} \int_{t_{0}}^{t} I \cdot \mathrm{d} t
$$

The non-stoichiometry $\delta$ of the sample was calculated according to

$$
\delta=\frac{2 \cdot n_{\mathrm{O}_{2}} \cdot M}{m},
$$

where $m$ denotes the mass and $M$ the molar mass of the oxidized samples $\left(\mathrm{Ce}_{x} \mathrm{Zr}_{1-x}\right)_{0.8} \mathrm{Y}_{0.2} \mathrm{O}_{1.9-\delta}$. To get the function of $\lg \delta$ vs. $\lg \left[p\left(\mathrm{O}_{2}\right) / \mathrm{bar}\right]$, the oxygen partial pressure $p \mathrm{O}_{2}^{\mathrm{II}}$ was subsequently changed within steps of oxidation at $600{ }^{\circ} \mathrm{C}$ and cooling down to room temperature. Data acquisition and controlling of the setup were performed with a personal computer and self-programmed LabView software program (LabView 2011 SP1, National Instruments).

One has to keep in mind that the non-stoichiometry $\delta$ obtained by the above described carrier gas coulometric technique in fact delivers $\Delta \delta$, relative to the highest oxidation state (oxygen, $600{ }^{\circ} \mathrm{C}$ ). But since this fixed-point is assumed to be achieved in every measurement step and the deviation thereof from the "real" stoichiometric point is very small $\left(\delta<10^{-4}\right)$, the assumption $\Delta \delta \approx \delta$ was considered to be valid. Moreover, the focus was placed on the high non-stoichiometric region rather than on the $\mathrm{n}$-p-transition point in this study.

\section{Results and discussion}

\subsection{Phase analysis and composition}

The chemical composition of the single crystals after the skull melting process was analysed by WDS. Within a small experimental error all target compositions were achieved (Table 1). Since zirconium metal is needed as ignition material for the skull melting process a little fraction of $\mathrm{Zr}$ could also be found in 100CZYO $(x=1.0)$. In spite of a small deviation from the desired to the achieved composition the labelling of the samples refers to the target composition.

Fig. 4 shows the results from XRD measurements of the powdered single crystals and polycrystalline reference samples. In the entire composition range the single crystals as well as the ceramic samples consist of a single cubic phase (fluorite-type). 
Table 1 Results of the WDS analysis for $\left(\mathrm{Ce}_{x} \mathrm{Zr}_{1-x}\right)_{0.8} \mathrm{Y}_{0.2} \mathrm{O}_{1.9-\delta}$ solid solutions

\begin{tabular}{llrrrl}
$\begin{array}{l}\text { Target } \\
\text { composition } / x\end{array}$ & Label & Ce/at\% & $\mathrm{Zr} / \mathrm{at} \%$ & $\mathrm{Y} / \mathrm{at} \%$ & $\begin{array}{l}\text { Achieved } \\
\text { composition }\end{array}$ \\
\hline 0.00 & 0CZYO & 0.00 & 78.75 & 21.24 & $\mathrm{Zr}_{0.79} \mathrm{Y}_{0.21} \mathrm{O}_{1.90}$ \\
0.10 & 10CZYO & 4.65 & 74.24 & 20.21 & $\mathrm{Ce}_{0.05} \mathrm{Zr}_{0.74} \mathrm{Y}_{0.20} \mathrm{O}_{1.90}$ \\
0.25 & 25CZYO & 17.74 & 61.23 & 21.02 & $\mathrm{Ce}_{0.18} \mathrm{Zr}_{0.61} \mathrm{Y}_{0.21} \mathrm{O}_{1.90}$ \\
0.50 & 50CZYO & 39.61 & 40.41 & 19.98 & $\mathrm{Ce}_{0.40} \mathrm{Zr}_{0.40} \mathrm{Y}_{0.20} \mathrm{O}_{1.90}$ \\
0.75 & 75CZYO & 60.00 & 19.62 & 20.38 & $\mathrm{Ce}_{0.60} \mathrm{Zr}_{0.20} \mathrm{Y}_{0.20} \mathrm{O}_{1.90}$ \\
1.00 & 100CZYO & 77.17 & 1.18 & 21.65 & $\mathrm{Ce}_{0.77} \mathrm{Zr}_{0.01} \mathrm{Y}_{0.22} \mathrm{O}_{1.89}$
\end{tabular}

The composition data exclude oxygen as a light element, and thus, the three metal components should add up to $100 \%$ in the ideal case.

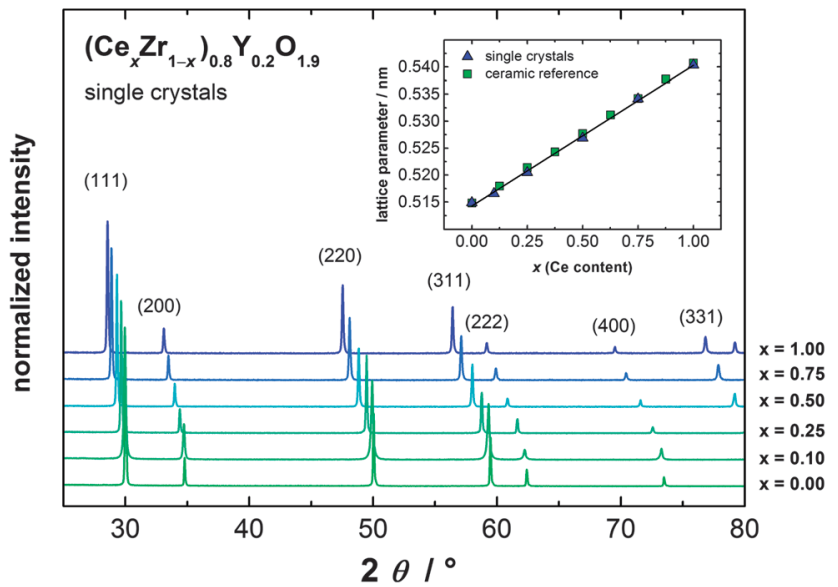

Fig. 4 X-ray powder diffraction patterns of powdered single crystals with different compositions. Reflection indices are marked with numbers in brackets $(h k l)$. The inset shows the lattice parameter (including the ceramic reference) as a function of composition.

We could find no evidence for the formation of a second phase and from experience it is evident that no phase change occurred during grinding of the single crystalline samples. The lattice parameters determined by Rietveld refinements are in good agreement with literature data. ${ }^{29,53}$ An increasing ceria content results in a shift of the observed reflections to smaller $2 \theta$ values. Since the ionic radius $r\left(\mathrm{Ce}^{4+}\right)=0.97 \AA$ of cerium ions is larger in comparison to the radius of zirconium ions $r\left(\mathrm{Zr}^{4+}\right)=0.84 \AA$, the lattice parameters expand with increasing ceria content resulting in a shift of the reflections to smaller diffraction angles. ${ }^{54}$

The linear relation between lattice parameter and ceria fraction indicates that Vegard's rule is fulfilled (Fig. 4 inset). There are no irregularities in the slope, i.e. the system appears to be fully miscible in the entire composition range as already reported by several authors. ${ }^{27,29,31,55,56}$ In contrast, Sammes et al. ${ }^{57}$ found a local maximum of the cell parameter $v s . x$ in the system $\left(\mathrm{CeO}_{2}\right)_{1-x}(8 \mathrm{YSZ})_{x}$ for $x \approx 0.5$ and drew the conclusion that $\mathrm{CeO}_{2}$ has a limited solubility in YSZ. Similar results from Hinatsu et $a l^{58}$ and Sakai et al. ${ }^{53}$ indicate a miscibility gap for $x=0.5-0.8$ in $\left(\mathrm{Ce}_{x} \mathrm{Zr}_{1-x}\right)_{0.8} \mathrm{Y}_{0.2} \mathrm{O}_{1.9-\delta}$ after long term annealing at elevated temperatures. There is no evidence that the single crystals investigated in this work are unstable within the experimental ranges of composition, temperature and time.
From the linear fit of the lattice parameter $a v s$. composition $x$ the following relations were extracted:

$a / \mathrm{nm}=(0.5143 \pm 0.0003)+(0.02603 \pm 0.0005) \cdot x($ single crystals $)$

$a / \mathrm{nm}=(0.5148 \pm 0.0001)+(0.02605 \pm 0.0002) \cdot x($ ceramic reference $)$

Within a minor deviation these relations are equal to previously reported results. Sakai et al. ${ }^{53}$ got the equation $a / \mathrm{nm}=0.5145+$ $0.0262 \cdot x$ for samples annealed at $1873 \mathrm{~K}$ (measured at $R T$ ) whereas Ananthapadmanabhan et al. ${ }^{27}$ found $a / \mathrm{nm}=0.5136+0.0264 \cdot x$ for the slightly different system $\left(\mathrm{Ce}_{x} \mathrm{Zr}_{1-x}\right)_{0.82} \mathrm{Y}_{0.18} \mathrm{O}_{1.91}$.

In addition to phase analysis by X-ray diffraction (XRD), Raman spectroscopy on small single crystals of each composition was performed (Fig. 5). Hereby, the crystallographic orientation was not considered. Raman spectroscopy offers high sensitivity to local coordination as well as to long range ordering in the cation and in the anion sublattice. Thus, this method is well suited to probe highly defective electrolyte solid solutions, and accordingly various studies on pure and acceptordoped $\mathrm{CeO}_{2}$ can be found in the literature. ${ }^{57,59-62}$ The cubic fluorite structure of $\mathrm{CeO}_{2}$ presents for symmetry reasons only one very strong triply degenerated Raman mode of first order at $460-465 \mathrm{~cm}^{-1}$. This vibrational mode with $F_{2 \mathrm{~g}}$ symmetry corresponds to the three-dimensional stretching of the coordinating oxygen cube around each metal cation centre. ${ }^{59,60,62}$ In yttriastabilized zirconia (YSZ) with the same crystal structure, this mode can be found around $600-610 \mathrm{~cm}^{-1} \cdot{ }^{63,64}$ Due to the high oxygen vacancy concentration in acceptor doped ceria-zirconia solid solutions the modes in all recorded spectra are very broad and of weak intensity. ${ }^{65}$ The translational symmetry of the

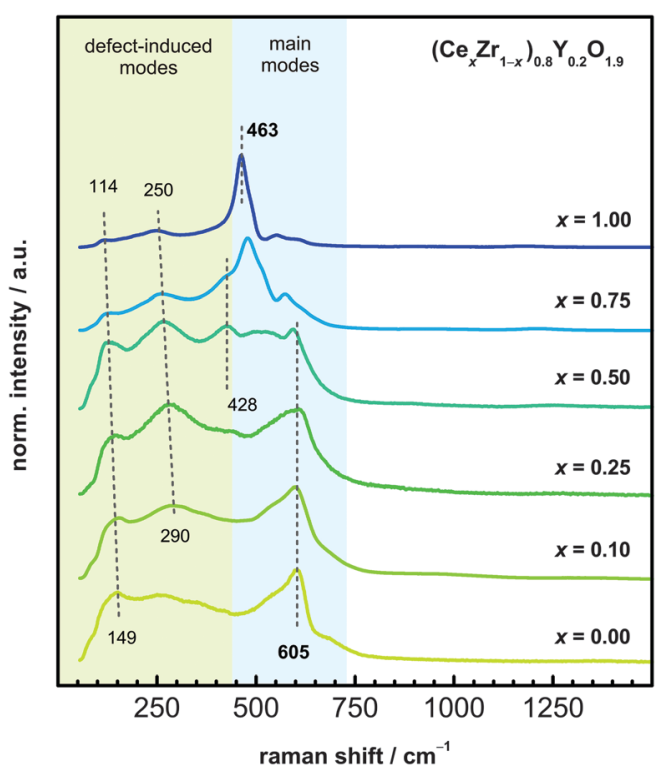

Fig. 5 Raman spectra of $\left(\mathrm{Ce}_{x} \mathrm{Zr}_{1-x}\right)_{0.8} \mathrm{Y}_{0.2} \mathrm{O}_{1.9-\delta}$ single crystal samples of different compositions. The spectra were normalized from 0 to 1 . A transition of the mode positions from $\mathrm{Ce}$-rich to $\mathrm{Zr}$-rich compositions can be observed. 
crystal system becomes more and more disturbed with increasing defect concentration, which strongly affects the phonon dispersion and breaks the wave vector $k=0$ selection rule. As a consequence, all phonons of the Brillouin zone may contribute to the Raman spectra. ${ }^{61,64}$ Therefore, several other modes between $100-450 \mathrm{~cm}^{-1}$ in the medium composition range arise $(x=0.25-0.75)$ as also observed by other groups. ${ }^{57,61,63,64}$ These modes are defect-induced, involving oxygen vacancies. Nakajima et al. took metal-vacancy and oxygen-vacancy defect clusters of the type $\mathrm{M}_{4} \mathrm{O}_{\mathrm{v}}$ (oxygen vacancy surrounded by four nearestneighbour metal ions), $\mathrm{O}_{6} \mathrm{O}_{\mathrm{v}}$ (oxygen vacancy surrounded by six next-nearest-neighbour oxygen ions, ignoring the surrounding four metal ions) and their linear combinations into account. With this approach they were able to explain their observed spectra very well. ${ }^{61}$ Two of these modes (114-149 $\mathrm{cm}^{-1}$ and $250-$ $290 \mathrm{~cm}^{-1}$ ) additionally show a transition from the Ce-rich to the Zr-rich compositions as found for the main $F_{2 \mathrm{~g}}$ feature. However, the main strong modes representing the tetragonal phase at $259 \mathrm{~cm}^{-1}$ and $641 \mathrm{~cm}^{-1}$ are missing. ${ }^{26,65,66}$ Therefore and in agreement with the literature and with the XRD results of the present work all sample compositions persist in the fluorite-type structure and there is no evidence for a miscibility gap or a second phase formation.

\subsection{Composition and temperature dependence of the total conductivity and activation energy for the charge transport}

The total conductivity $\sigma$ was firstly measured via impedance spectroscopy in the temperature range of $250 \leq \theta /{ }^{\circ} \mathrm{C} \leq 800$ at a constant oxygen partial pressure of $\mathrm{pO}_{2}=0.21$ bar. $^{67}$ During preliminary measurements it turned out that the capacitance of the samples was very small $(<1 \mathrm{pF})$ and therefore got close to the capacitance of the lead wires and the sample holder. The signal quality suffered strongly from that circumstance and very high frequencies would have been needed to resolve a complete semicircle. As these high frequencies could not be realized with the present setup, different capacitors were connected parallel to the sample (Fig. 6). Parallel capacitances are added up to a "total" capacitance and upon rising the total capacitance, the peak frequency of the resulting semicircle is shifted downwards into the frequency range of the measurement according to

$$
\omega_{\max }=\frac{1}{R C},
$$

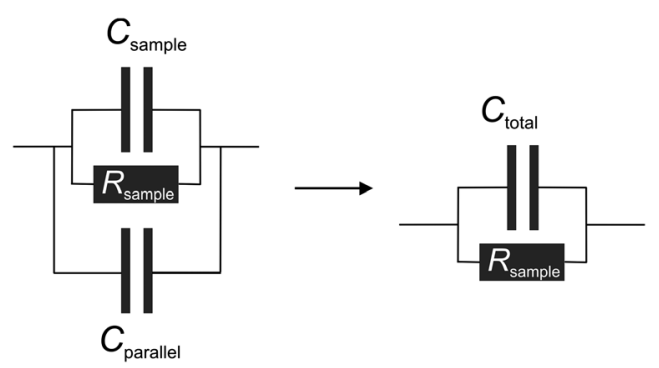

Fig. 6 Parallel connection of a capacitor $C_{\text {parallel }}$ and the sample $\left(R_{\text {sample }} /\right.$ $C_{\text {sample }}$ ) results in a total capacitance $C_{\text {total }}$ while the sample resistance is not affected. where $\omega_{\max }$ denotes the peak frequency of the semicircle, $R$ the sample resistance and $C$ the total capacitance. The sample resistance remains unaffected. To verify this procedure, comparative experiments with and without parallel capacitors were performed (Fig. 7). For a single crystalline sample an equivalent circuit of only one parallel $R C$-element is expected. Highly conductive silver electrodes, as used in the present setup, are often "invisible" in impedance spectroscopy. However, the spectrum of the sample without parallel capacitor shows a highly contracted, insufficient developed and depressed semicircle. The high frequency section lies far beyond the accessible frequency range of the measurement setup. Parallel connected capacitors cause, due to the reduction of the peak frequency, complete semicircles and an improvement of the obtained signal quality. The inset in Fig. 7 clarifies that the sample resistance is not affected within a small experimental error. Since parallel connection of capacitors does not change the equivalent circuit of the sample, the procedure is physically reasonable, if only the sample resistance is of interest. One has to note that the information content of the measurement is not increased by this procedure, but the signal quality is significantly improved which means that the measurement becomes more accurate. Therefore, this procedure is applied for all further samples of this study. We like to note that we have not found the use of "shunt capacitors" documented in the literature, which is surprising in view of the simple procedure.

Fig. 8 presents the total electrical conductivity of CZYO in the whole composition range as a function of temperature. Since the measurements were carried out in air, the resulting conductivities are mainly determined by ionic transport. The course of the curves shows a bending down at high temperatures, more or less pronounced depending on the respective composition. Furthermore, a strong dependence on the ceria content is observed. With increasing ceria content the conductivity shows a minimum at $x=0.5$. Here, the decrease in conductivity is more than one order of magnitude. This behaviour has been reported by several other groups for polycrystalline samples as well, ${ }^{27,29,30}$ which is therefore in good agreement with single crystals investigated in the present work. However, such a strong decrease in conductivity with respect to the ceria content is surprising at first glance, since the charge carrier concentration (oxygen vacancies) is fixed in the whole composition range by yttria doping. Therefore, these results clearly indicate a changing mobility of the ionic charge carriers. As an explanation in general the association of defects, blocking effects or oxygen vacancy ordering has been considered. ${ }^{68-70}$ It is interesting to note that a conductivity minimum and an activation energy maximum are often observed in disordered ion conductors with two mobile charge carriers upon gradual replacement of one ion by the other one (e.g. two different alkali ions in a glass), defining the "mixed alkali effect". ${ }^{71}$ There are different sites in the framework, which are energetically favoured for one ion but unfavoured for the other one. The theoretical explanation of the mixed alkali effect grounds on the structural mismatch of the coordination of two different mobile ions and the required lattice relaxation upon jumps. This approach may be expanded to oxygen conducting 

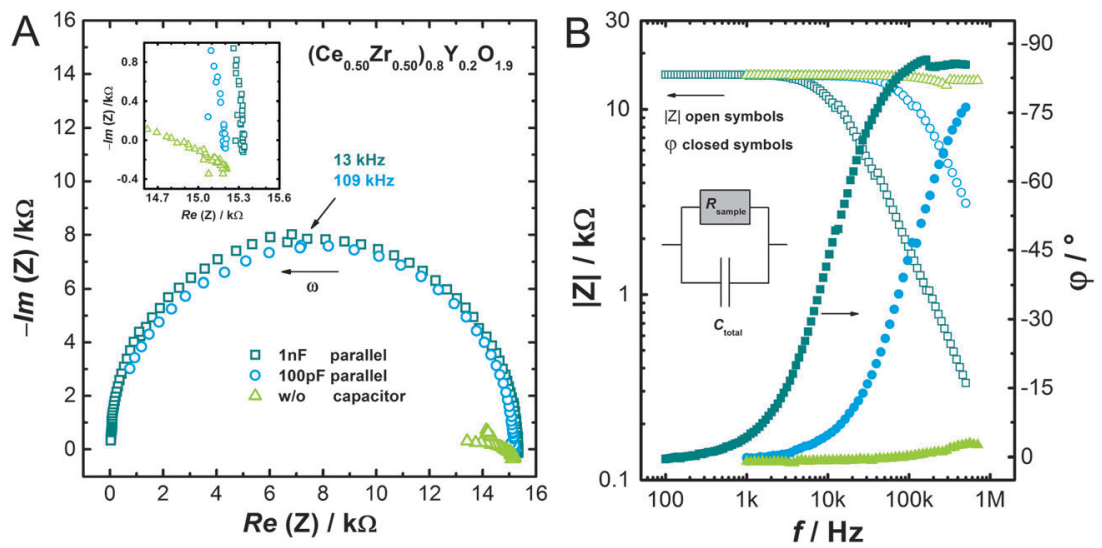

Fig. 7 Typical impedance spectra of single crystalline $\left(\mathrm{Ce}_{x} \mathrm{Zr}_{1-x}\right)_{0.8} \mathrm{Y}_{0.2} \mathrm{O}_{1.9-\delta}$ solid solutions for composition $x=0.5$ measured in air at $800{ }^{\circ} \mathrm{C}(\mathrm{A}$ Nyquist, $B$ Bode representation). For comparison, different spectra with and without parallel connected capacitors are shown. The signal quality is highly improved with parallel connected capacitors while the sample resistance stays unaffected. Inset A: magnification of the low frequency semicircle base point.

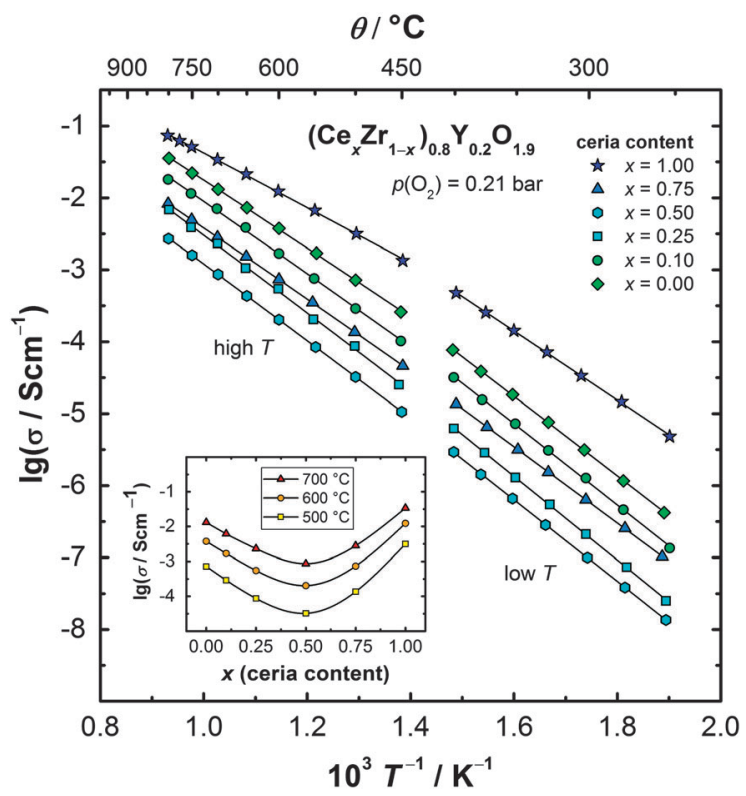

Fig. 8 Total conductivity as a function of temperature for different compositions of $\left(\mathrm{Ce}_{x} \mathrm{Zr}_{1-x}\right)_{0.8} \mathrm{Y}_{0.2} \mathrm{O}_{1.9-\delta}$ at an oxygen partial pressure of $\mathrm{pO}_{2}=0.21$ bar. Solid lines indicate a linear fit for the high and low temperature regime. Inset: Total conductivity vs. ceria content for three selected temperatures.

systems with different cations and hence different oxygen sites. Yang et al. suggest that the conductivity minimum arises from a competition of two different factors with increasing Ce content $(x)::^{30}$ (1) the formation of defect associates is favoured accompanied by a decrease in mobility. (2) The lattice parameter increases offering wider paths for the oxygen vacancy migration. These oppositional trends may lead to a conductivity minimum as a function of $x$. We suggest that structural effects similar to the mixed alkali effect may also contribute to the formation of the maximum.

Additionally, the activation energy $E_{\mathrm{a}}$ and the preexponential factor of the conductivity $\sigma_{0}$ were evaluated from the temperature dependence according to eqn (24), where $\sigma$ denotes the total conductivity, $k$ the Boltzmann factor and $T$ the absolute temperature.

$$
\ln [\sigma T]=\ln \sigma_{0}-\frac{E_{\mathrm{a}}}{k T}
$$

Due to the aforementioned bending the activation energy was determined separately for the high and low temperature regime (refer to Fig. 8). In comparison to the conductivity, the activation energy for the oxygen transport (Fig. 9) shows an opposite trend with a maximum for both temperature regimes in the medium composition range at about $x=0.3-0.4$, as observed in the mixed alkali effect. This topic has already been subjected in DFT calculations by Chen et al. for $\mathrm{Ce}-\mathrm{Zr}-\mathrm{O}^{22}$ and by Xiao et al. for Ce-Th-O. ${ }^{72}$ The same explanation as for the conductivity may be applied for the activation energy. For a detailed discussion about that topic the reader is referred to the literature. ${ }^{68-70,73-76}$ However, at this point a brief explanation is given: the activation energy for the oxygen transport consists of a term addressing the migration energy of a "free" oxygen vacancy and a second term resulting from the dissociation energy to remove a vacancy from an associated defect. If the tendency for associated defects increases with increasing Ce content, and in opposite the migration of vacancies is facilitated, the maximum in activation energy can easily be understood.

The pre-exponential factor $\sigma_{0}$ by trend decreases with increasing $x$, but we observe a local minimum at $x=0.5$, where $\sigma$ has its minimum. The pre-exponential factor can be interpreted as proportional to the "free" charge carrier concentration and therefore fits well to the above given explanations.

To summarize, the minimum in the total conductivity of the system $\left(\mathrm{Ce}_{x} \mathrm{Zr}_{1-x}\right)_{0.8} \mathrm{Y}_{0.2} \mathrm{O}_{1.9-\delta}$ as a function of composition $x$ is mainly explained by a "size effect" resulting from different ionic radii of $\mathrm{Ce}^{4+}$ and $\mathrm{Zr}^{4+}$, leading to structural relaxation once oxygen ions jump from one site with a specific coordination to a neighbouring site with different coordination. Moreover, the tendency for defect association between $\mathrm{Y}^{3+}$ and oxygen vacancy was proposed to be affected. A more detailed 


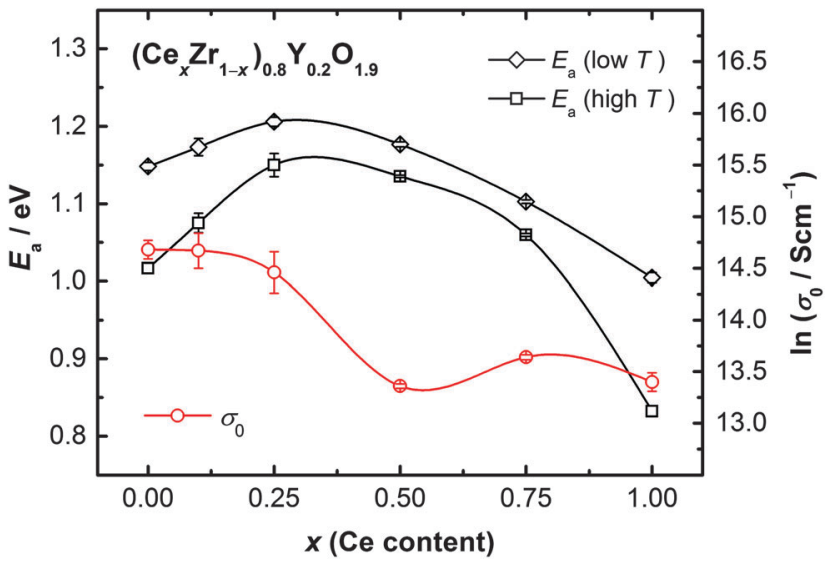

Fig. 9 Activation energy $E_{\mathrm{a}}$ for the high and low temperature regime (see Fig. 8) and pre-exponential factor $\sigma_{0}$ (high $T$ regime) of the total conductivity as a function of composition $x$. The solid lines connect data points for visual purposes.

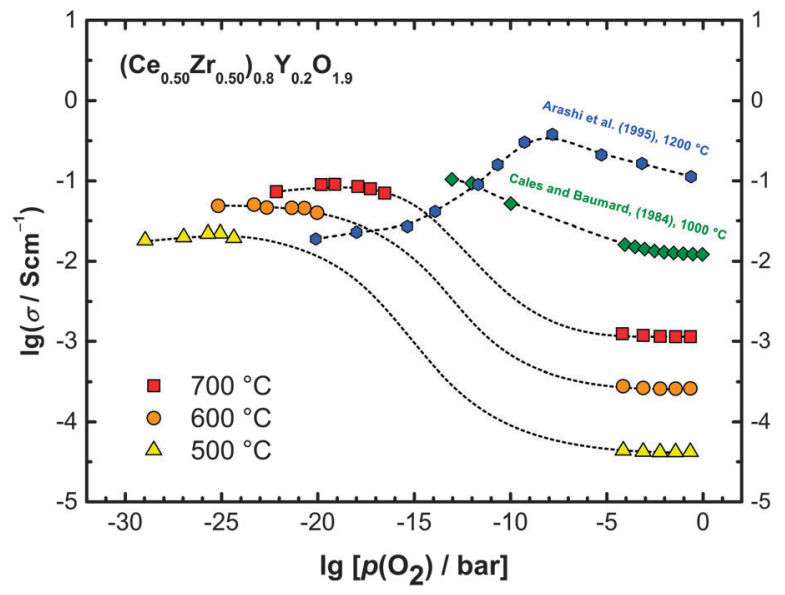

Fig. 10 Total conductivity of 50CZYO as a function of oxygen partial pressure for three different temperatures. For comparison, data of polycrystalline samples from literature are shown. Dashed lines are drawn to guide the eye.

discussion about the energetic behaviour of different dopants in ceria can be found in Minervini et al. ${ }^{77}$

\subsection{Partial conductivities and the transference number of oxygen ions}

The total conductivity was measured as a function of oxygen partial pressure in the temperature range of $500 \leq \theta /{ }^{\circ} \mathrm{C} \leq 700$. Exemplary results for 50CZYO are presented in Fig. 10. We like to note that in the medium partial pressure regime, due to the use of $\mathrm{CO}-\mathrm{CO}_{2}$ gas mixtures, stable values for $p \mathrm{O}_{2}$ could not be established and therefore no measurements were performed in this range. Dashed lines were plotted to show an interpolated trend of the curves in this regime, primarily to guide the eye.

The isothermal $p \mathrm{O}_{2}$ dependence of 50CZYO shows the same course at each temperature but with a shift on the $p \mathrm{O}_{2}$ scale. Higher temperatures cause reduction (positive entropy contribution by oxygen gas) which results in a shift to higher oxygen partial pressures with increasing temperature. In taking a closer look, one can divide the course of the curves into three regions:

(1) At high oxygen partial pressures there is a region of constant conductivity. According to the acceptor defect model this region is dominated by ionic conductivity due to yttria doping (see Fig. 1, region II).

(2) With decreasing $p \mathrm{O}_{2}$ the conductivity starts to increase until it reaches,

(3) a second plateau with a small fading to lower conductivity.

The generally applied ideal point defect model predicts an increasing total conductivity, if the electronic conductivity starts to become higher than the oxygen ion conductivity. The expected slope is $-1 / 4$ if the vacancy concentration is still constant or $-1 / 6$, if the vacancy concentration starts to increase by strong reduction at very low oxygen partial pressures. Hence, the appearance of the second plateau at low $\mathrm{pO}_{2}$ cannot be explained with the conventional defect model. However, the formation of a second plateau or even a distinct maximum for some compositions along with the observation of a strong deviation from the underlying defect model has already been reported for polycrystalline CZYO. ${ }^{28,31,32,34,78,79}$ Unfortunately, there are only a few data available for the same compositions and for the same temperature range as surveyed in this work. Some literature data of polycrystalline samples with the same composition but for different temperatures are added for comparison in Fig. 10. Although the temperatures are higher, a similar trend can be noticed as compared to our own results.

To explain this unusual behaviour we have to take a deeper look into the transport properties and the defect chemistry of the investigated materials. Hence, additional measurements of the partial electronic conductivity and the oxygen ion transference number were performed.

In the following, we first discuss the Hebb-Wagner measurements used to derive the partial electronic conductivities.

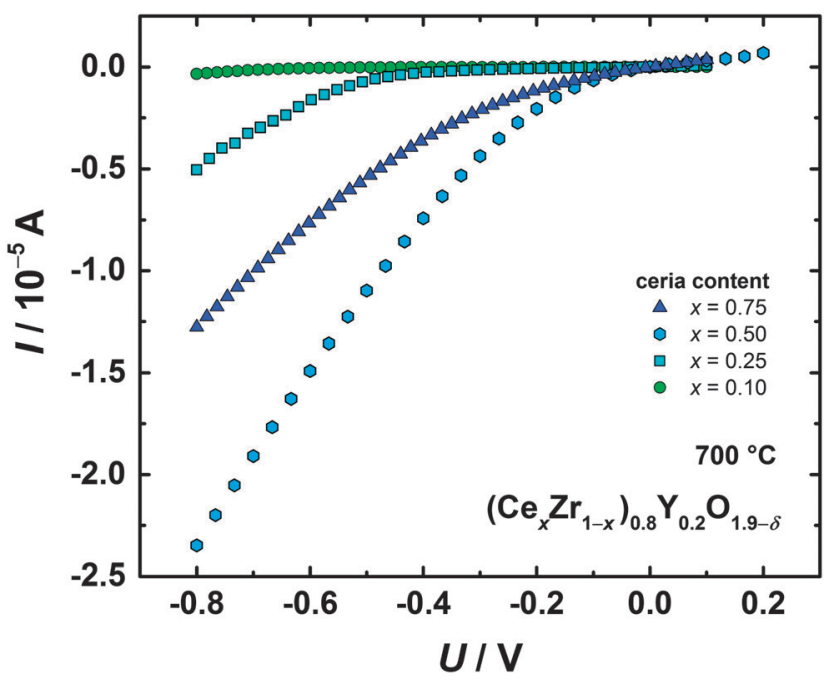

Fig. $11 \mathrm{I}-U$-curves of different sample compositions measured at $700{ }^{\circ} \mathrm{C}$ in the Hebb-Wagner microcontact setup. 
Fig. 11 gives an overview of the steady state current-voltage curves at a blocking Pt microcontact with regard to four single crystal compositions with varying ratios Ce:Zr at $700{ }^{\circ} \mathrm{C}$. Each point $(I, U)$ of the curves in Fig. 11 was obtained by monitoring the current relaxation after applying each corresponding voltage step until a steady state value was reached ( $c f$. Section 3.5). The relaxation times usually ranged around 60 to $200 \mathrm{~s}$ at $700{ }^{\circ} \mathrm{C}$. Although the contact resistances were different for the various compositions (the lowest have been observed for the composition 25CZYO), the relaxation times were quite similar for all sample compositions at the same temperature.

All samples show a strong increase of the measured current $I$ in the highly reducing region (negative voltage), which is based on the increasing electronic contribution. It is evident in Fig. 11 that the sample with the ratio $n(\mathrm{Ce}) / n(\mathrm{Zr})=1 / 1$ shows the largest values for current and slope in the entire negative voltage range corresponding to a clear maximum of the electronic conductivity within the series of samples with differing ratios Ce:Zr. As expected, the sample with the lowest cerium concentration $n(\mathrm{Ce}) / n(\mathrm{Zr})=1 / 9$ shows a rather low electronic conductivity.

Fig. 12 gives an overview of the evaluation of the steady state $I-U$ curves of the sample 50CZYO at three temperatures and for a larger voltage sweep (see Section 3.5 for details of the evaluation). The radius of the microcontact was $190 \mu \mathrm{m}$. As Fig. 12 shows slightly oxidizing as well as strongly reducing conditions were attainable yielding a set of data in the intermediate partial pressure range which otherwise was not accessible by equilibration with gas mixtures. A remarkable trend towards very low oxygen partial pressures is particularly evident for the sample 50CZYO in Fig. 12. In contrast to the expectations based on the conventional defect models of acceptor doped ceria or zirconia alone, the curves show an intermediate plateau feature and thus no continuous increase of the electronic conductivity with expected slopes only between $-1 / 4$ and $-1 / 6$.

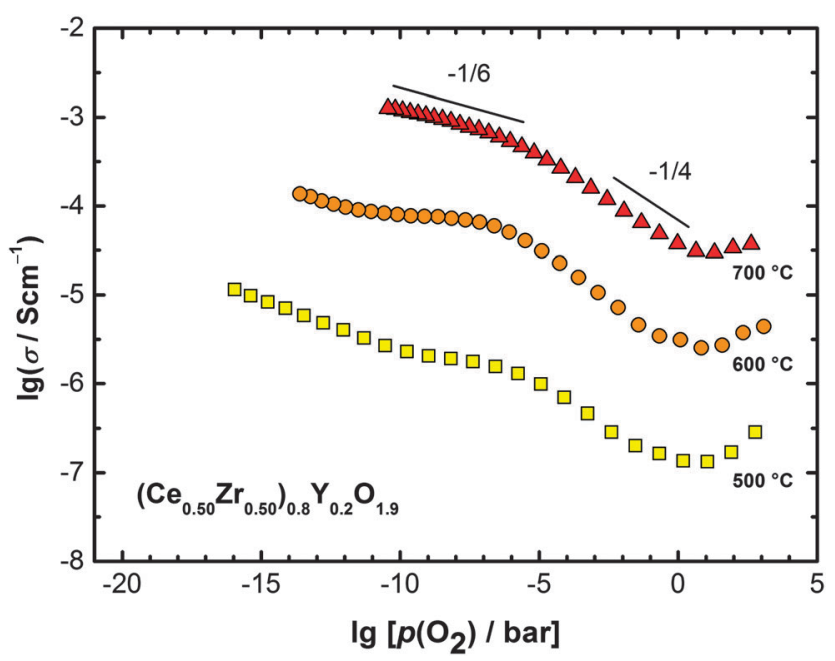

Fig. 12 Evaluation of the partial electronic conductivities from the HebbWagner polarization curves comparable to Fig. 11 for the single crystal $50 C Z Y O$ at three temperatures.

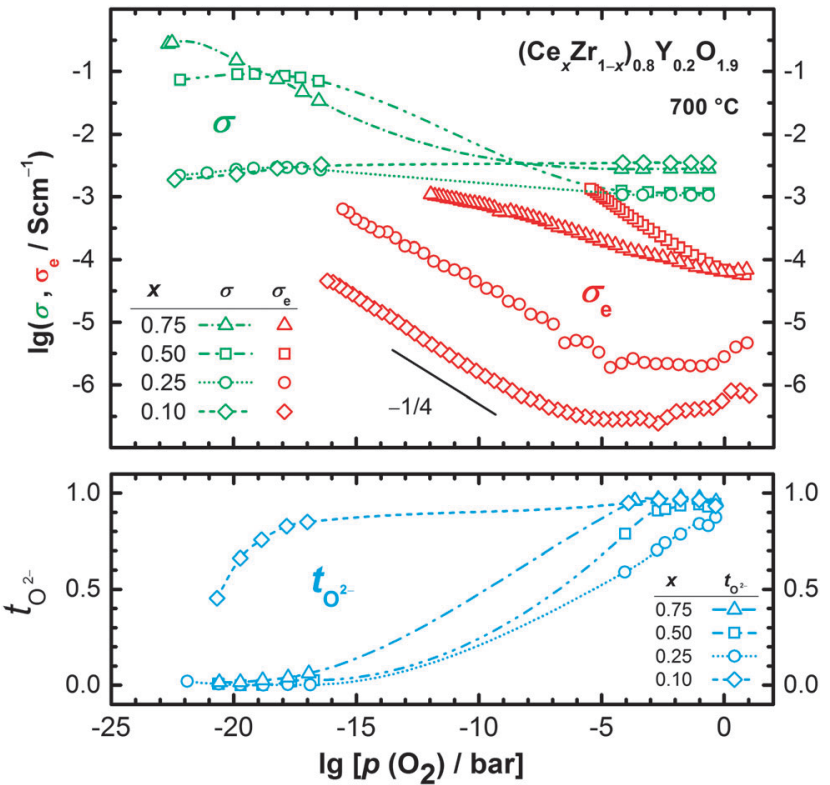

Fig. 13 Total conductivity, electronic conductivity (obtained from HebbWagner polarisation) and the oxygen ion transference number for CZYO as a function of oxygen partial pressure at a constant temperature of $700{ }^{\circ} \mathrm{C}$. Dashed lines are drawn for better visualisation.

Therefore, starting in the intermediate partial pressure range below $10^{-6}$ bar, a more complicated interaction of electrons (i.e. $\mathrm{Ce}^{3+}$ ions) with majority defects such as acceptor ions and/or oxygen vacancies becomes visible and supports the above mentioned observation in the course of the total conductivities with oxygen partial pressure. Fig. 13 therefore gives a summarizing overview and comparison of the different conductivities in addition to the measured oxygen transference numbers (note: $\sigma_{\mathrm{e}}$ was obtained from Hebb-Wagner polarisation). Concerning the total conductivity $\sigma$, each composition of CZYO offers a different and specific course with respect to $\mathrm{pO}_{2}$ (Fig. 13). But especially at low oxygen partial pressures a clear trend is observed. Composition 75CZYO exhibits the highest conductivity and shows no plateau in the investigated $p \mathrm{O}_{2}$ range. With decreasing $x$ (Ce content) the conductivity decreases and the tendency for the formation of a plateau is enhanced. The conductivity of $10 \mathrm{CZYO}$ even decreases with decreasing $\mathrm{pO}_{2}$ without showing a plateau.

In the high oxygen partial region, the electronic conductivity $\sigma_{\mathrm{e}}$ increases around its minimum for all compositions with a slope of approx. $-1 / 4$ tending to $-1 / 6$ for lower $p \mathrm{O}_{2}$. The deviations from this as already mentioned in the preceding paragraph tend to become important for very low oxygen partial pressures and more enhanced at higher temperatures. In addition, $\sigma_{\mathrm{e}}$ shows a strong dependence on the cerium concentration $x$. At $\lg \left[p \mathrm{O}_{2} / \mathrm{bar}\right]=-0.67$ (air), for instance, the absolute values of the partial conductivities $\sigma_{\mathrm{e}}$ are by a factor of $10^{1}$ to $10^{3}$ lower than the respective total conductivities. As mentioned above, the total conductivity at high oxygen partial pressures is therefore dominated by ionic transport, and the electronic transference number is in the low percent range. 
In general, the transference number of oxygen ions confirms the results of the conductivity measurements at high and medium oxygen partial pressures but also give some new information. At low $p \mathrm{O}_{2}$ the ionic transference number becomes very small $\left(t_{\mathrm{O}^{2-}}<0.05\right)$. Therefore the course of the total conductivity is almost completely determined by electronic transport, except for 10CZYO. For this composition the oxygen ion transference number first remains high and then decreases again at low $\mathrm{pO}_{2}$ down to $t_{\mathrm{O}^{2-}} \approx 0.5$. The total conductivity is nearly constant in the whole $\mathrm{O}_{2}$ range while the electronic conductivity increases with decreasing $\mathrm{pO}_{2}$. Thus, $10 \mathrm{CZYO}$ is a real mixed conductor with virtually equal contributions of ions and electrons at low oxygen partial pressures.

In summary, the observed total conductivities show an unusual course as a function of oxygen partial pressure and a strong deviation from the usually applied point defect model with acceptor doping, especially at low $\mathrm{pO}_{2}$. A low oxygen ion transference number at low $\mathrm{pO}_{2}$ reveals mainly electronic charge transport. For further defect chemical analysis the charge carrier concentration and the mobility are essential. Thus, the oxygen non-stoichiometry was measured as a function of $\mathrm{pO}_{2}$, which gives access to both quantities.

\subsection{Non-stoichiometry and oxygen storage capacity (OSC)}

The non-stoichiometry of CZYO was measured by a carrier gas coulometric technique at $700{ }^{\circ} \mathrm{C}$ depending on $\mathrm{pO}_{2}$ (see Section 3.6). Fig. 14 shows a typical coulometric oxygen exchange experiment for 50CZYO. After the sample chamber had been well flushed with the desired oxygen partial pressure the temperature was raised to the target temperature $\left(10{ }^{\circ} \mathrm{C} \mathrm{min}^{-1}\right)$. Meanwhile, the sample started to release oxygen and titration cell 2 had to compensate this excess oxygen with a lowered current. This current curve vs. time has a peak shape and its integration gives the amount of titrated charge from which the amount of oxygen was calculated (eqn (19)). Then, using eqn (20), nonstoichiometry $\delta$ was calculated and plotted against $p \mathrm{O}_{2}$ (Fig. 15). At high oxygen partial pressures the course of $\lg \delta v s$. $\lg p \mathrm{O}_{2}$ takes a slope of $-1 / 4$ for all ceria contents and then reaches a plateau

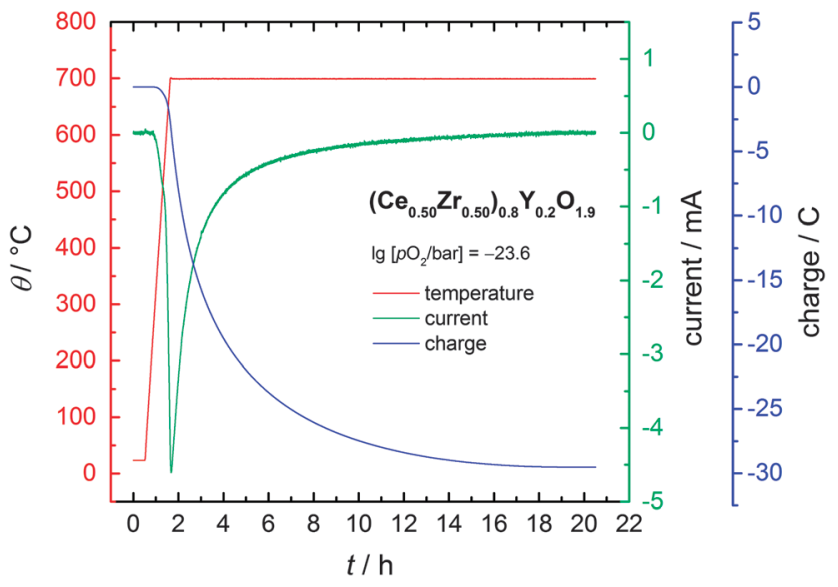

Fig. 14 Chart of typical coulometric oxygen exchange experiment: Temperature, electrolysis current and charge as a function of time.

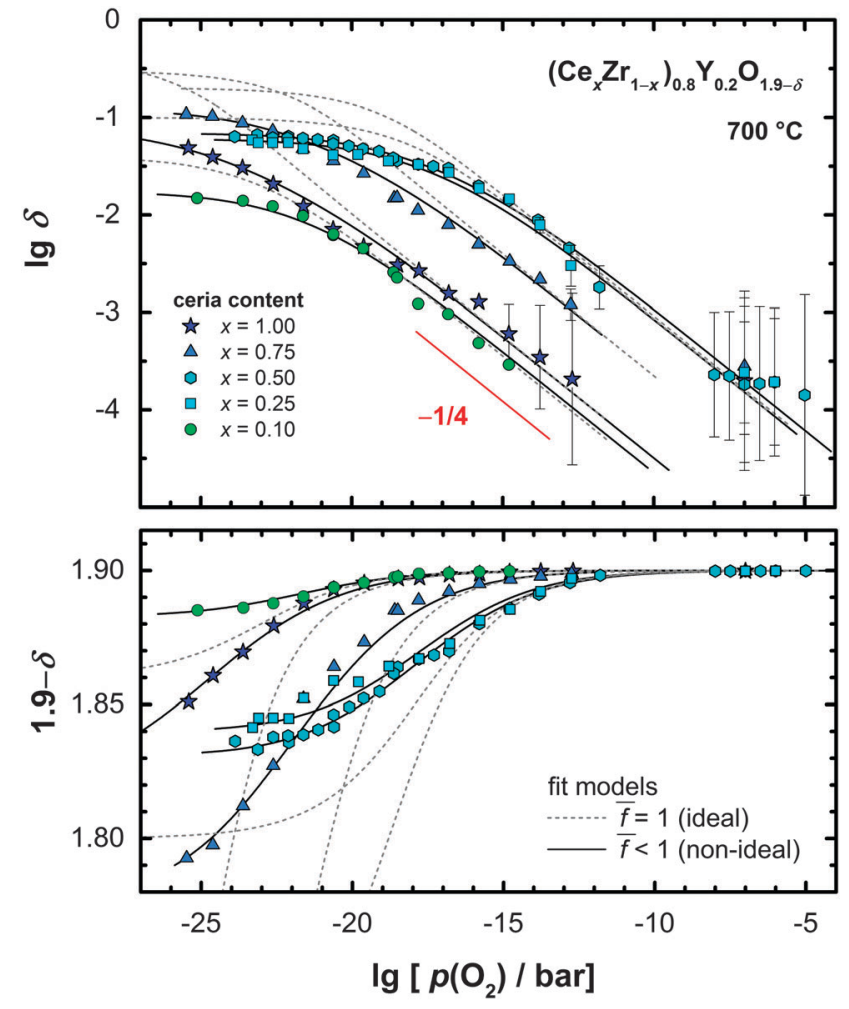

Fig. 15 Oxygen non-stoichiometry plotted as $\lg \delta$ and $1.9-\delta$ for $\left(\mathrm{Ce}_{x} \mathrm{Zr}_{1-x}\right)_{0.8} \mathrm{Y}_{0.2} \mathrm{O}_{1.9-\delta}$ against oxygen partial pressure. Fitting was performed once for ideal conditions $(\bar{f}=1)$ with fixed Ce content according to the molar fraction $x_{\mathrm{Ce}}$ of $\mathrm{Ce}$ (dotted lines) and additionally with activity coefficient $\bar{f}<1$ as a fitting parameter (solid lines). Refer to eqn (31)-(36).

at low $\mathrm{pO}_{2}$. The absolute values of $\lg \delta$ and the position of the curves differ with respect to $x$. For a better (alternative) visualisation the non-logarithmic representation $1.9-\delta$ was added. In a first attempt it was tried to fit the obtained curves with the simple acceptor-based point defect model (Section 2). Therefore, the concentrations of defect species in eqn (3) have to be described as a function of $\delta$,

$$
\begin{gathered}
{\left[\mathrm{Ce}_{\mathrm{Ce}}^{\prime}\right]=2 \delta} \\
{\left[\mathrm{V}_{\mathrm{O}}^{\bullet \bullet}\right]=0.1+\delta} \\
{\left[\mathrm{O}_{\mathrm{O}}^{\times}\right]=1.9-\delta} \\
{\left[\mathrm{Ce}_{\mathrm{Ce}}^{\times}\right]=x_{\mathrm{Ce}}-2 \delta=0.8 \cdot x-2 \delta}
\end{gathered}
$$

where $x_{\mathrm{Ce}}$ denotes the molar fraction of Ce per formula unit at the stoichiometric point $(\delta=0)$ depicted as $0.8 \cdot x$ in the case of $\left(\mathrm{Ce}_{x} \mathrm{Zr}_{1-x}\right)_{0.8} \mathrm{Y}_{0.2} \mathrm{O}_{1.9-\delta}$. Inserting eqn (25)-(28) into eqn (3) an expression of $\lg p \mathrm{O}_{2}$ as a function of $\delta$ with $K_{1}$ as a parameter is obtained:

$$
\lg p \mathrm{O}_{2}=\lg K_{1}+\lg \left[\frac{(0.8 \cdot x-2 \delta)^{4}(1.9-\delta)^{2}}{(2 \delta)^{4}(0.1+\delta)^{2}}\right]
$$

The fit of eqn (29) to the present data (Fig. 15, grey dashed lines) results in a good agreement at high but in a strong deviation at low oxygen partial pressures. At a first glance, the calculated non-stoichiometry appears to be overestimated but 
the fit reaches exactly the maximum $\delta$ value which corresponds to the fully reduced state of Ce in CZYO. Hence, the simple point defect model does not hold. To improve the model, Otake et $a .^{35}$ and Schneider et al. ${ }^{80}$ assumed the formation of defect associates $\left(\mathrm{Ce}_{\mathrm{Ce}}^{\prime} \mathrm{V}_{\mathrm{O}}^{\bullet \bullet}\right)^{\bullet},\left(\mathrm{Ce}_{\mathrm{Ce}}^{\prime} \mathrm{V}_{\mathrm{O}}^{\bullet \bullet} \mathrm{Ce}_{\mathrm{Ce}}^{\prime}\right)$ and $\left(\mathrm{Y}_{\mathrm{Ce}}^{\prime} \mathrm{V}_{\mathrm{O}}^{\bullet \bullet}\right)^{\bullet}$ and were able to describe the observed deviation quite well. ${ }^{35}$ We tried to adapt this approach to the present data but did not achieve a satisfying agreement between model and experimental data.

Taking a closer look to published data for the nonstoichiometry of nominally pure $\mathrm{CeO}_{2}$ and solid solutions of (Ce, $\mathrm{M}) \mathrm{O}_{2-\delta}(\mathrm{M}=\mathrm{Zr}, \mathrm{Y}, \mathrm{Gd})$ we find that the maximum $\delta$ value with respect to the Ce content was not reached in any study. $3,6,26,35,80-82$ Especially at lower temperatures $\left(\theta<800{ }^{\circ} \mathrm{C}\right)$ and at very low oxygen partial pressures the curves of $\lg \delta v s$. $\lg \mathrm{pO}_{2}$ bend down or attain a plateau by a factor of approx. 1/2 below the theoretical value of $\delta$. Thus, it appears that only a fraction of $\mathrm{Ce}^{4+}$ in the solid solution is accessible for the reduction. In the mathematical derivation of the defect model, the law of mass action for the oxygen release reaction was simplified by using concentrations instead of activities (eqn (3)). Obviously, this assumption is not valid in the present case and the use of activities becomes mandatory.

It is known from liquid electrolytes that the activity of charged species differs from their nominal concentrations. One approach to calculate activity coefficients of dilute electrolyte solutions makes use of the Debye-Hückel theory which relies on the electrostatic interaction. ${ }^{83}$ The Debye-Hückel theory is strictly only applicable at low defect concentrations, and therefore more complex descriptions are required for higher concentrations. ${ }^{84-88}$

Instead, in the case of highly defective $\mathrm{AgCl}, \mathrm{AgBr}, \mathrm{AgI}$ and $\mathrm{PbF}_{2}$, it was shown that non-ideal effects can also be described by a simple cubic root law

$$
R T \ln f_{ \pm}=-J_{ \pm} x_{ \pm}^{1 / 3}
$$

where $f_{ \pm}$denotes the mean activity coefficient, $J_{ \pm}$a concentration independent parameter and $x_{ \pm}$the molar fraction of defects. ${ }^{89}$ The non-ideal energetic effects are described by a superposition of a perfect crystal lattice with a defect lattice. In terms of a mean field approach parameter $J_{ \pm}$depends on the effective Madelung constants of the ideal crystal and its defect lattice ${ }^{90}$ both of which can be obtained by theoretical calculations. ${ }^{91}$

Following this approach we introduce the mean activity coefficient as an additional parameter into the fitting of $\lg \delta v s . \lg p \mathrm{O}_{2}$. The concentrations in eqn (3) are replaced by activities following

$$
K_{2}=\frac{a\left(\mathrm{Ce}_{\mathrm{Ce}}^{\prime}\right)^{2} a\left(\mathrm{~V}_{\mathrm{O}}^{\bullet \bullet}\right) a\left(\mathrm{O}_{2}\right)^{1 / 2}}{a\left(\mathrm{Ce}_{\mathrm{Ce}}^{\times}\right)^{2} a\left(\mathrm{O}_{\mathrm{O}}^{\times}\right)},
$$

where $a(\mathrm{i})$ denotes the respective chemical activity of the defects and regular structure elements i (i.e. $a(\mathrm{i})=f_{\mathrm{i}} \cdot x_{\mathrm{i}}, f_{\mathrm{i}}$ and $x_{\mathrm{i}}$ depict the activity coefficient and the molar ratio, respectively). The activities are then expressed as a function of $\delta$, with the mean activity coefficient $\bar{f}$ and the molar fraction of $\mathrm{Ce}, x_{\mathrm{Ce}}$, as a parameter:

$$
\begin{gathered}
a\left(\mathrm{Ce}_{\mathrm{Ce}}^{\prime}\right)=2 \delta \\
a\left(\mathrm{~V}_{\mathrm{O}}^{\bullet \bullet}\right)=\bar{f} \cdot 0.1+\delta
\end{gathered}
$$

$$
\begin{gathered}
a\left(\mathrm{O}_{\mathrm{O}}^{\times}\right)=\bar{f} \cdot 1.9-\delta \\
a\left(\mathrm{Ce}_{\mathrm{Ce}}^{\times}\right)=\bar{f} \cdot x_{\mathrm{Ce}}-2 \delta \\
a\left(\mathrm{O}_{2}\right) \approx p_{\mathrm{O}_{2}}
\end{gathered}
$$

Under consideration of eqn (32)-(36), eqn (31) was solved to an expression of $\lg p \mathrm{O}_{2} \propto \delta$ with $\bar{f}$ and $K_{2}$ as parameters. The authors are well aware that $\bar{f}$ is in principle a function of defect concentration, i.e. of $p \mathrm{O}_{2}$, but in a first-order approximation we assume that $\bar{f}$ is constant. This is justified as the change in total defect concentration (be aware that the yttria dopant causes a high defect concentration in any case) with $p \mathrm{O}_{2}$ being small, see below. Applying the resulting term to the fit of the experimental data gives acceptable and improved agreement especially in the low oxygen partial pressure region where the simple acceptor defect model failed (Fig. 15, black solid lines). Hence, the improved point defect model which includes chemical activities appears to be meaningful and obviously the activity coefficient $\bar{f}$ can be well regarded as a nearly constant with respect to $\mathrm{pO}_{2}$. In retrospect this assumption appears to be justified as the overall defect concentration only slightly changed over the $\mathrm{pO}_{2}$ range (approx. factor 1.5). All fit parameters are depicted in Table 2. Obviously the picture of non-interacting defects is not valid and significant interaction comes into play at these high defect concentrations.

Other simple and common activity models were also tried to describe the measured data. The general approach is to provide only charged defects with an activity coefficient. Then, eqn (31) can be written as

$$
K_{3}=\frac{a\left(\mathrm{Ce}_{\mathrm{Ce}}^{\prime}\right)^{2} a\left(\mathrm{~V}_{\mathrm{O}}^{\bullet \bullet}\right) p_{\mathrm{O}_{2}}^{1 / 2}}{\left[\mathrm{Ce}_{\mathrm{Ce}}^{\times}\right]^{2}\left[\mathrm{O}_{\mathrm{O}}^{\times}\right]},
$$

with concentrations and activities equal to

$$
\begin{gathered}
a\left(\mathrm{Ce}_{\mathrm{Ce}}^{\prime}\right)=\bar{f} \cdot 2 \delta \\
a\left(\mathrm{~V}_{\mathrm{O}}^{\bullet \bullet}\right)=\bar{f} \cdot(0.1+\delta) \\
{\left[\mathrm{O}_{\mathrm{O}}^{\times}\right]=1.9-\delta} \\
{\left[\mathrm{Ce}_{\mathrm{Ce}}^{\times}\right]=x_{\mathrm{Ce}}-2 \delta} \\
=0.8 \cdot x-2 \delta
\end{gathered}
$$

\begin{tabular}{|c|c|c|c|c|}
\hline$x$ & $\bar{f}$ & $\lg K_{2}$ & $\delta$ & $\mathrm{OSC} / \mu \mathrm{mol} \mathrm{O} \mathrm{g}^{-1}$ \\
\hline 0.00 & - & - & - & - \\
\hline 0.10 & 0.44 & -24.1 & 0.0063 & 25.3 \\
\hline 0.25 & 0.60 & -19.9 & 0.041 & 157 \\
\hline 0.50 & 0.35 & -19.8 & 0.058 & 207 \\
\hline 0.75 & 0.41 & -23.5 & 0.036 & 119 \\
\hline 1.00 & 0.20 & -26.1 & 0.0071 & 22.1 \\
\hline
\end{tabular}

The activity coefficient was then calculated according to the respective models after Table 3 . Unfortunately, eqn (37) and none of the interaction models lead to an acceptable fit result.

Table 2 Fit results for the non-stoichiometry of $\left(\mathrm{Ce}_{x} \mathrm{Zr}_{1-x}\right)_{0.8} \mathrm{Y}_{0.2} \mathrm{O}_{1.9-\delta}$ solid solutions

For $x=0.0$ (without $\mathrm{Ce}$ ) no measurement was performed since no significant non-stoichiometry was expected. $\delta$ and OSC are stated for $\lg \left[\mathrm{pO}_{2} / \mathrm{bar}\right]=-20.6$ and $700{ }^{\circ} \mathrm{C}$. 
Table 3 Applied interaction models for activity coefficients

\begin{tabular}{ll}
\hline Denotation & Formula \\
\hline Ideal & $f=1$ \\
$1-\delta$ & $f=A \cdot(1-\delta)$ \\
$1-\sqrt{\delta}$ & $f=A \cdot(1-\sqrt{\delta})$ \\
Debye-Hückel & $\lg f=-A \cdot \sqrt{x_{\text {def }}}$ \\
Cubic-root-law & $R T \ln f=-J \cdot x_{\text {def }}^{1 / 3}$
\end{tabular}

Where $f$ denotes the activity coefficient, $A$ and $J$ additional fit parameters and $x_{\mathrm{def}}$ the concentration of the respective defect.

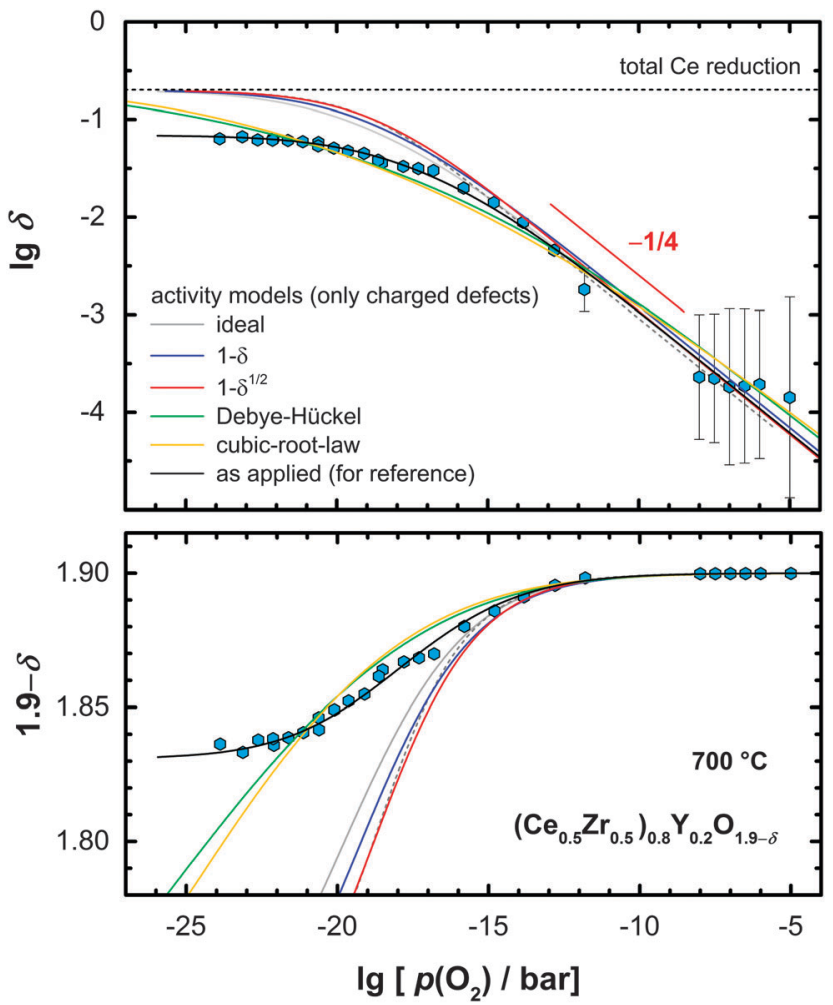

Fig. 16 Oxygen non-stoichiometry plotted as $\lg \delta$ and $1.9-\delta$ for 50CZYO against oxygen partial pressure. Fitting was performed for different activity models only for charged defects (eqn (37)-(41), Table 3). The "as applied" model is shown for reference.

Fig. 16 exemplarily shows the fitted curves for 50CZYO. All of them finally reach the full reduction of $\mathrm{Ce}^{4+}$ to $\mathrm{Ce}^{3+}$ at very low $p \mathrm{O}_{2}$, which does in no way reproduce the experimental data, which show a "damping" of the reduction at low $p \mathrm{O}_{2}$. The reduction of $\mathrm{Ce}^{4+}$ is somehow stopped at a certain level of approx. 50\%. Obviously, the listed approaches do not describe the defect interactions at low $p \mathrm{O}_{2}$ properly. Only the unconventional approach as used above can describe the course of the non-stoichiometry. The authors admit that there might be contributions by additional defect types, which have not been considered. This has to be clarified in further studies.

To illustrate the dependence on the cerium content, $1.9-\delta$ was plotted at a specific partial pressure of $\lg \left[p \mathrm{O}_{2} / \mathrm{bar}\right]=-20.6$ as a function of $x$ (Fig. 17). The highest oxygen deficit (nonstoichiometry) was obtained for values of $0.4 \leq x \leq 0.5$. This

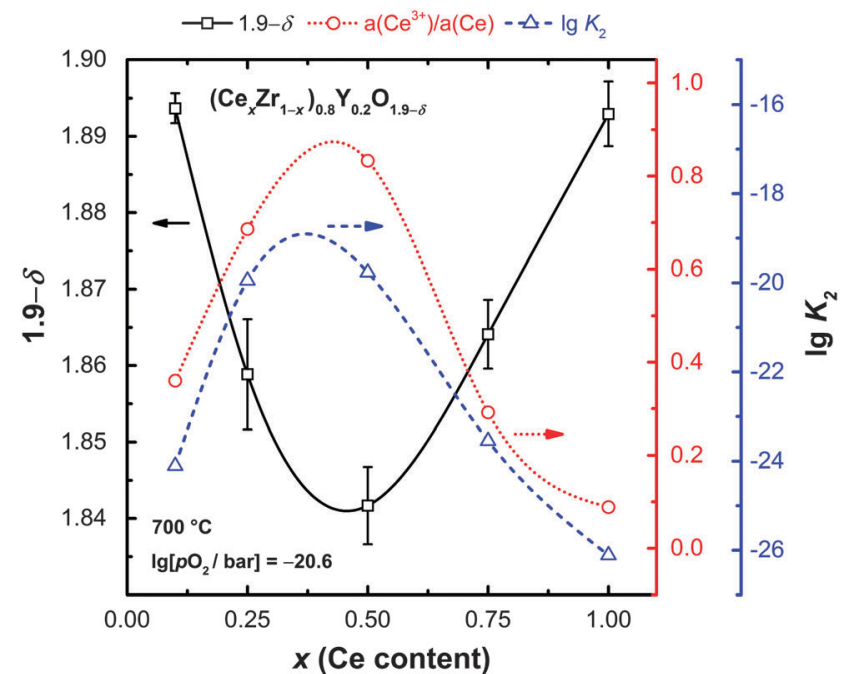

Fig. 17 Oxygen non-stoichiometry $1.9-\delta$, the ratio of $\frac{a\left(\mathrm{Ce}^{3+}\right)}{a(\mathrm{Ce})}$ and $\lg K_{2}$ as a function of Ce content $x$ at $\lg \left[\mathrm{pO}_{2} / \mathrm{bar}\right]=-20.6$ and $700{ }^{\circ} \mathrm{C}$.

behaviour coincides well with TPR (Temperature Programmed Reduction) experiments on Ce-Zr-O catalyst materials to determine the oxygen storage capacity (OSC). In several theoretical and experimental studies it was found that a ratio of $n(\mathrm{Ce}) / n(\mathrm{Zr})$ $\approx 1$ gives the highest OSC as well as the best catalytic performance. ${ }^{17-19,21-23}$ In contrast to these results nanocrystalline mesoporous $(\mathrm{Ce}, \mathrm{Zr}) \mathrm{O}_{2}$ shows surprisingly different behaviour. ${ }^{92}$ Here the non-stoichiometry (OSC) shows a linear trend with the highest value for pure $\mathrm{CeO}_{2}$. However, it was also observed that a higher fraction of $\mathrm{Zr}$ leads to a higher degree of reduction (i.e. $\left.n\left(\mathrm{Ce}^{3+}\right) / n(\mathrm{Ce})\right)$. Thus, the formation of oxygen vacancies is, as in the bulk samples, eased in the presence of $\mathrm{Zr}$. The altered behaviour of mesoporous $(\mathrm{Ce}, \mathrm{Zr}) \mathrm{O}_{2}$ was attributed to its large surface exposed to the gas atmosphere. Obviously, the defect properties of near-surface regions are quite different from the bulk material.

Interestingly, $\frac{a\left(\mathrm{Ce}^{3+}\right)}{a(\mathrm{Ce})}$ and $\lg K_{2}$, obtained from the fit (Fig. 17), also have their maximum at cerium contents of $0.4 \leq x \leq 0.5$. The parameter $\frac{a\left(\mathrm{Ce}^{3+}\right)}{a(\mathrm{Ce})}$, defined as the ratio between the activities of reduced Ce to the total amount of Ce (degree of reduction), gives a measure of the utilisation of cerium during the reduction. A higher value represents an enhanced efficiency concerning the application of cerium as OSC material. The maximum of the equilibrium constant $\lg K_{2}$ reveals that at this point the reduction is thermodynamically most favoured compared to the other compositions, which is in line with the aforementioned results of theoretical studies. The obtained OSC values for CZYO single crystals show the same trend and order magnitude as literature data for real catalyst materials ${ }^{20,93}$ (Table 2). This good agreement encourages the predictability of properties in polycrystalline systems from single crystal data.

At this point the question arises how to further improve the OSC. Besides the (nano-, meso-) structuring of the material one approach concerning defect chemical considerations may be 
the co-doping of ceria-zirconia systems with other redox active transition metals. Possible candidates are praseodymium $\left(\mathrm{Pr}^{3+} / \mathrm{Pr}^{4+}\right),{ }^{94}$ titanium $\left(\mathrm{Ti}^{3+} / \mathrm{Ti}^{4+}\right)$, iron $\left(\mathrm{Fe}^{2+} / \mathrm{Fe}^{3+}\right)$ and manganese $\left(\mathrm{Mn}^{2+} / \mathrm{Mn}^{3+} / \mathrm{Mn}^{4+}\right)$. A second redox couple which is redoxactive within the required $\mathrm{pO}_{2}$ range can add to the OSC, of course further increasing the extrinsic defect concentration at low $\mathrm{pO}_{2}$.

In summary, the non-stoichiometry of CZYO single crystals as a function of oxygen partial pressure at $700{ }^{\circ} \mathrm{C}$ was successfully fitted with a modified point defect model which uses activities instead of concentrations - introducing a constant activity coefficient. In accordance with previous studies the highest non-stoichiometry was found for 50CZYO.

\subsection{Charge carrier concentration, electronic mobility and defect structure analysis}

The charge carrier mobility is, along with the conductivity, a further important material parameter of electrolytes to understand the underlying charge transport properties. It can be obtained from a combination of conductivity and non-stoichiometry data. The electronic conductivity is given as

$$
\sigma_{\mathrm{e}}=e_{0} \cdot \mu_{\mathrm{e}} \cdot n,
$$

where $\sigma_{\mathrm{e}}$ and $n$ stand for the electronic conductivity and the electron concentration, respectively. To obtain the electronic conductivity in a preferably wide range of oxygen partial pressure, the results of both applied techniques were combined. Therefore, in the high $p \mathrm{O}_{2}$ region the partial electronic conductivity was taken directly from the ion blocking method and at lower $p \mathrm{O}_{2}$ it is calculated from the total conductivity and the oxygen ion transference number as given by

$$
\sigma_{\mathrm{e}}=\sigma \cdot\left(1-t_{\mathrm{O}^{2-}}\right) .
$$

The charge carrier concentration $n=\beta \cdot\left[\mathrm{Ce}_{\mathrm{Ce}}^{\prime}\right]$, in $\mathrm{cm}^{-3}$, was calculated by multiplying the molecular number density $\left(\beta=\frac{1}{V}\right.$, where $V$ is the unit cell volume calculated from the cubic lattice parameter) with the concentration per formula unit. Eqn (42) was then solved to

$$
\mu_{\mathrm{e}}=\frac{\sigma_{\mathrm{e}}}{e_{0} \cdot \beta \cdot\left[\mathrm{Ce}_{\mathrm{Ce}}^{\prime}\right]},
$$

with $\left[\mathrm{Ce}_{\mathrm{Ce}}^{\prime}\right]=2 \delta$. In Fig. 18 all relevant parameters are displayed as a function of $\mathrm{pO}_{2}$. For all compositions the charge carrier concentration $n$ increases monotonously with decreasing $p \mathrm{O}_{2}$ at which $50 \mathrm{CZYO}$ and $25 \mathrm{CZYO}$ attain a plateau and $75 \mathrm{CZYO}$ and 10CZYO slightly bend down. The highest values are obtained for $50 \mathrm{CZYO}$ and $25 \mathrm{CZYO}$ in the upper and for $75 \mathrm{CZYO}$ in the very low $p \mathrm{O}_{2}$ region.

Concerning the partial electronic conductivity a similar behaviour was found. However, the formation of plateaus is more pronounced for 50CZYO and 25CZYO as already observed for the electron concentration ( $c f$. also Fig. 12). Taking a look on the electron mobility discloses the relationship between conductivity and charge carrier concentration. In some reports the electron mobility is suggested to be mainly responsible for the

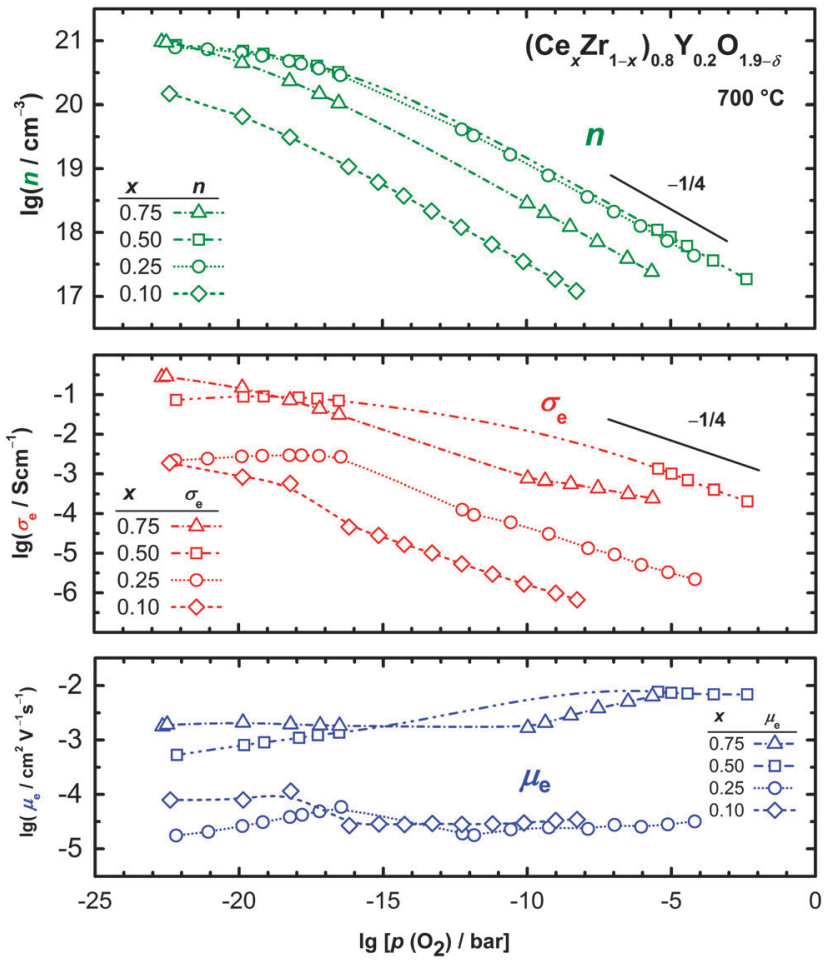

Fig. 18 Charge carrier concentration, conductivity and mobility of electrons as a function of oxygen partial pressure at $700{ }^{\circ} \mathrm{C}$. For an improved visualisation broken lines connect the data points.

unusual $p \mathrm{O}_{2}$ dependence of the conductivity. ${ }^{31,32}$ In the present work, a dependence of the electron mobility on $p \mathrm{O}_{2}$ is verified for all compositions. Samples 75CZYO, 50CZYO and 25CZYO exhibit a decrease in mobility while the mobility in 10CZYO increases upon falling $\mathrm{pO}_{2}$. The strongest drop of about 1.5 orders of magnitude is shown by 50CZYO. In general, the mobility increases with increasing Ce content. This is not surprising, since electrons can only move between Ce ions according to the polaron hopping model. Thus, the mobilities of electrons in $25 \mathrm{CZYO}$ and $10 \mathrm{CZYO}$ are by far the lowest.

The absolute values range from $\mu_{\mathrm{e}}=10^{-2}$ to $10^{-5} \mathrm{~cm}^{2} \mathrm{~V}^{-1} \mathrm{~s}^{-1}$. Blumenthal and Panlener $^{95}$ found a mobility of $6 \times$ $10^{-3} \mathrm{~cm}^{2} \mathrm{~V}^{-1} \mathrm{~s}^{-1}$ for pure ceria at $700{ }^{\circ} \mathrm{C}$ and low oxygen partial pressure, which is close to the value of 75CZYO in the present work. For comparison, the oxygen vacancy mobility of 50CZYO in air is calculated to be $\mu_{\mathrm{v}}\left(700^{\circ} \mathrm{C}\right)=5.3 \times 10^{-6} \mathrm{~cm}^{2} \mathrm{~V}^{-1} \mathrm{~s}^{-1}$.

The defect chemistry of CZYO single crystals can be summarized as follows: the total conductivity shows a specific course for each composition and in the low $\mathrm{pO}_{2}$ region there is a strong deviation from the simple acceptor point defect model when an ideal solution of defects is assumed. The oxygen ion transference number reveals predominant electronic conductivity at low $p \mathrm{O}_{2}$. Measurement and analysis of the non-stoichiometry proves that defects in CZYO are strongly interacting, and defect activities instead of concentrations have to be used. Assuming a constant activity coefficient in a first order approximation the course of the non-stoichiometry, and therefore the electron concentration, can be well described. 
The electronic conductivity bends down at low $p \mathrm{O}_{2}$ and has a maximum for 50CZYO and 25CZYO along with a decrease in electron mobility. Both of these compositions exhibit a high degree of reduction, i.e. $\frac{\left[\mathrm{Ce}^{3+}\right]}{[\mathrm{Ce}]}$, of up to $40 \%$ at $\lg \left[p \mathrm{O}_{2} / \mathrm{bar}\right]=$ -20.6. A high degree of reduction results in a site restriction within the polaron hopping model, since less $\mathrm{Ce}^{4+}$ sites are available for hopping electrons. Hence, the diffusion coefficient $D_{\mathrm{e}} \propto\left[\mathrm{Ce}^{4+}\right]$ becomes proportional to the concentration of unreduced cerium ions $\left[\mathrm{Ce}^{4+}\right]$. Since mobility and the diffusion coefficient of charged species are related by the Nernst-Einstein equation

$$
\mu_{\mathrm{e}}=\frac{e \cdot D_{\mathrm{e}}}{k T}
$$

one obtains $\sigma_{\mathrm{e}} \propto\left[\mathrm{Ce}^{3+}\right] \cdot\left[\mathrm{Ce}^{4+}\right]$. This mathematical function of the form $f(c)=c(1-c)$ has a maximum at $c=0.5$ (half reduction of $\mathrm{Ce}$ ). This relation has often been given as explanation for the unusual course of the electronic conductivity in some previous studies. $^{32,96}$ But only an independent determination of the charge carrier concentration, as carried out in this work, can verify this assumption.

The course of the ionic conductivity in the high $p \mathrm{O}_{2}$ region is well explained by acceptor doping. But a statement about its course at low $\mathrm{pO}_{2}$ is rather notional, since the EMF method for determining the transference number is mainly suited for the majority charge carrier. At very low $\mathrm{pO}_{2}$ the oxygen ion transference number becomes small $\left(t_{\mathrm{O}^{2-}}<0.01\right)$ and the method more and more inaccurate. An increasing oxygen vacancy concentration with decreasing $p \mathrm{O}_{2}$ is undoubted. In several studies the dependence of the ionic conductivity on the vacancy concentration (i.e. concentration of the acceptor dopant) has been surveyed. ${ }^{68-70,73-76}$ In all cases a maximum was observed at a trivalent dopant concentration of $c a$. 15-20 at\% which has its origin in electrostatic interaction and/or vacancy ordering due to the high defect concentration. In this study the acceptor dopant $\left(\mathrm{Y}^{3+}\right)$ concentration was already fixed at 20 at\%. Any further oxygen vacancies formed by decreasing $p \mathrm{O}_{2}$ therefore most likely lead to a slightly decreasing ionic conductivity for all compositions. However, a decrease of the ionic conductivity was mainly observed for $50 \mathrm{CZYO}$ and $25 \mathrm{CZYO}$.

\section{Conclusion}

This study presents the first single crystal reference data for the $\mathrm{CeO}_{2}-\mathrm{ZrO}_{2}-\mathrm{Y}_{2} \mathrm{O}_{3}$ oxide solution. The electrical transport and the non-stoichiometry of $\left(\mathrm{Ce}_{x} \mathrm{Zr}_{1-x}\right)_{0.8} \mathrm{Y}_{0.2} \mathrm{O}_{1.9-\delta}(0 \leq x \leq 1)$ single crystals were studied by measuring the total electrical conductivity, the partial electronic conductivity, the oxygen ion transference number and the non-stoichiometry depending on $p \mathrm{O}_{2}$ and $T$. On the basis of these measurements, a consistent defect model with a corresponding extended data set was determined for CZYO in the entire range of composition (i.e. variation of the $\mathrm{Ce} / \mathrm{Zr}$ ratio).

In agreement with previous reports, an unusual course of the total conductivity as a function of $p \mathrm{O}_{2}$ was observed, which cannot be explained by the "classical" acceptor point defect model. Examination of the non-stoichiometry confirms that the defects in the solid solution system $\mathrm{CeO}_{2}-\mathrm{ZrO}_{2}-\mathrm{Y}_{2} \mathrm{O}_{3}$ interact strongly and have to be treated as non-ideal with corresponding activity coefficients. A point defect model which explicitly includes defect interactions was introduced. Using this model, the obtained data could be fitted with good accuracy.

Finally it turned out that the course of the total conductivity depending on $\mathrm{pO}_{2}$ is mainly influenced by at least two main effects: (1) for the reason of non-ideality of the system, a diminished electron concentration in the low $p \mathrm{O}_{2}$ region was observed as actually expected when an ideal solution defect model is assumed. (2) A reduced electron mobility was found at low oxygen partial pressures due to site restriction effects according to the polaron hopping model. We like to emphasize that the electron mobility is for the first time determined for a ceria-based electrolyte of various compositions in almost the full practically accessible range of $\mathrm{pO}_{2}$ over nearly 25 orders of magnitude.

The superior oxygen storage capacity and catalytic performance of the specific composition $n(\mathrm{Ce}) / n(\mathrm{Zr}) \approx 1$ over other ratios were encircled to a maximum in the equilibrium constant for the reduction and to a maximum in the electronic conductivity at medium and high $\mathrm{pO}_{2}$ for this composition, which qualifies the material to be a good mixed conductor. This feature is essential for a fast oxygen exchange in catalytic applications, since for a chemical diffusion of $\mathrm{O}_{2}$ into the bulk both electronic and ionic charge transport are required to be efficient.

Common approaches for the calculation of concentration dependent activity coefficients failed to describe the obtained non-stoichiometry data in this study (e.g. Debye-Hückel, cubicroot-law). Only the somewhat unconventional and unphysical approach with a single constant interaction parameter appears to be sufficient and explains most of the deviations from the ideal defect solution models. However the physical meaning of this approach remains unclear and has to be resolved in future studies. There might be additional defect types involved which have not been considered here.

\section{Acknowledgements}

This work was funded by the German Research Foundation (DFG projects Ja648/21-1, Le781/14-1 and Wi952/9-1) and also supported by the LOEWE program STORE-E (State of Hessen) within the Laboratory of Materials Research at JLU.

\section{References}

1 I. V. Vinokurov and V. A. Ioffe, Sov. Phys. Solid State, 1969, 11, 207.

2 R. N. Blumenthal, P. W. Lee and R. J. Panlener, J. Electrochem. Soc., 1971, 118, 123-129.

3 H. L. Tuller and A. S. Nowick, J. Electrochem. Soc., 1979, 126, 209-217. 
4 H. L. Tuller and A. S. Nowick, J. Phys. Chem. Solids, 1977, 38, 859-867.

5 P. Kofstad and A. Z. Hed, J. Am. Ceram. Soc., 1967, 50, 681-682.

6 R. J. Panlener, R. N. Blumenthal and J. E. Garnier, J. Phys. Chem. Solids, 1975, 36, 1213-1222.

7 Y.-P. Xiong, H. Kishimoto, K. Yamaji, M. Yoshinaga, T. Horita, M. E. Brito and H. Yokokawa, Electrochem. Solid-State Lett., 2010, 13, B21.

8 Y.-P. Xiong, H. Kishimoto, K. Yamaji, M. Yoshinaga, T. Horita, M. E. Brito and H. Yokokawa, Solid State Ionics, 2011, 192, 476-479.

9 P. R. L. Keating, D. O. Scanlon, B. J. Morgan, N. M. Galea and G. W. Watson, J. Phys. Chem. C, 2012, 116, 2443-2452.

10 T. Zacherle, A. Schriever, R. A. De Souza and M. Martin, Phys. Rev. B: Condens. Matter Mater. Phys., 2013, 87, 134104.

11 B. C. H. Steele, Solid State Ionics, 2000, 129, 95-110.

12 N. Chaubey, B. N. Wani, S. R. Bharadwaj and M. C. Chattopadhyaya, Solid State Sci., 2013, 20, 135-141.

13 K. C. Anjaneya, G. P. Nayaka, J. Manjanna, G. Govindaraj and K. N. Ganesha, J. Alloys Compd., 2013, 578, 53-59.

14 C. Chatzichristodoulou, M. Sogaard, J. Glasscock, A. Kaiser, S. r. P. V. Foghmoes and P. V. Hendriksen, J. Electrochem. Soc., 2011, 158, F73.

15 R. Di Monte and J. Kašpar, Catal. Today, 2005, 100, 27-35.

16 A. Trovarelli, C. de Leitenburg, M. Boaro and G. Dolcetti, Catal. Today, 1999, 50, 353-367.

17 J. Kašpar, P. Fornasiero and M. Graziani, Catal. Today, 1999, 50, 285-298.

18 A. Trovarelli, Comments Inorg. Chem., 1999, 20, 263-284.

19 J. J. Delgado, X. Chen, J. A. Pérez-Omil, J. M. RodríguezIzquierdo and M. A. Cauqui, Catal. Today, 2012, 180, 25-33.

20 M. Sugiura, Catal. Surv. Asia, 2003, 7, 77-87.

21 H.-F. Wang, X.-Q. Gong, Y.-L. Guo, Y. Guo, G. Z. Lu and P. Hu, J. Phys. Chem. C, 2009, 113, 10229-10232.

22 H. T. Chen and J. G. Chang, J. Chem. Phys., 2010, 132, 214702.

23 J. Paier, C. Penschke and J. Sauer, Chem. Rev., 2013, 113, 3949-3985.

24 G. Chiodelli, G. Flor and M. Scagliotti, Solid State Ionics, 1996, 91, 109-121.

25 J. H. Lee, S. M. Yoon, B. K. Kim, J. Kim, H. W. Lee and H. S. Song, Solid State Ionics, 2001, 144, 175-184.

26 M. Kuhn, S. R. Bishop, J. L. M. Rupp and H. L. Tuller, Acta Mater., 2013, 61, 4277-4288.

27 P. V. Ananthapadmanabhan, N. Venkatramani, V. K. Rohatgi, A. C. Momin and K. S. Venkateswarlu, J. Eur. Ceram. Soc., 1990, 6, 111-117.

28 H. Arashi, H. Naito and M. Nakata, Solid State Ionics, 1995, 76, 315-319.

29 V. Rührup and H. D. Wiemhofer, Z. Naturforsch., B: J. Chem. Sci., 2006, 61, 916-922.

30 F. Yang, X. Zhao and P. Xiao, J. Power Sources, 2011, 196, 4943-4949.

31 B. Cales and J. F. Baumard, J. Electrochem. Soc., 1984, 131, 2407-2413.
32 C. H. Lee and G. M. Choi, Solid State Ionics, 2000, 135, 653-661.

33 J. H. Lee, J. Kim, S. W. Kim, H. W. Lee and H. S. Song, Solid State Ionics, 2004, 166, 45-52.

34 Y. Xiong, K. Yamaji, N. Sakai, H. Kishimoto, T. Horita, M. E. Brito and H. Yokokawa, J. Electrochem. Soc., 2006, 153, A2198.

35 T. Otake, H. Yugami, K. Yashiro, Y. Nigara, T. Kawada and J. Mizusaki, Solid State Ionics, 2003, 161, 181-186.

36 X. Guo, W. Sigle and J. Maier, J. Am. Ceram. Soc., 2003, 86, 77-87.

37 A. Tschöpe, S. Kilassonia and R. Birringer, Solid State Ionics, 2004, 173, 57-61.

38 X. Guo, S. Mi and R. Waser, Electrochem. Solid-State Lett., 2005, 8, J1.

39 D. K. Lee, L. Kogel, S. G. Ebbinghaus, I. Valov, H. D. Wiemhoefer, M. Lerch and J. Janek, Phys. Chem. Chem. Phys., 2009, 11, 3105-3114.

40 I. Valov, V. Rührup, R. Klein, T. C. Rödel, A. Stork, S. Berendts, M. Dogan, H. D. Wiemhöfer, M. Lerch and J. Janek, Solid State Ionics, 2009, 180, 1463-1470.

41 W. Assmus and N. Whippey, Chem. Ing. Tech., 1983, 55, 716-717. 42 T. Roisnel and J. Rodriguez-Carvajal, in Epdic 7: Proceedings of the Seventh European Powder Diffraction Conference Held May 20-23, 2000 in Barcelona, Spain, ed. R. Delhez and E. J. Mittemeijer, Trans Tech Publication, 2000.

43 L. Heyne, in Mass transport in oxides; Proceedings of a symposium held at Gaithersburg, ed. A. D. Franklin and J. B. Wachtman, U.S. National Bureau of Standards, Maryland, Gaithersburg, October 22-25, 1967, 1968, pp. 149-164.

44 D. K. Lee, C. C. Fischer, I. Valov, J. Reinacher, A. Stork, M. Lerch and J. Janek, Phys. Chem. Chem. Phys., 2011, 13, 1239-1242.

45 C. Wagner, Z. Phys. Chem. B, 1933, 21, 25-41.

46 C. Wagner, Proc. 7th Meeting Int. Comm. Electrochem. Thermodynamics and Kinetics, Butterworths, 1957, p. 361.

47 J.-P. Eufinger, M. Daniels, K. Schmale, G. Ulbrich, M. Lerch, H.-D. Wiemhöfer and J. Janek, $\mathrm{Ta}_{2} \mathrm{O}_{5}$-doped $\mathrm{CeO}_{2}$ single crystals with unusual tantalum redox state - Defect chemistry and electrical transport in an oxygen storage phase, J. Mater. Chem. A, 2014, submitted.

48 M. H. Hebb, J. Chem. Phys., 1952, 20, 185-190.

49 H.-D. Wiemhöfer, Habilitation Thesis, Eberhard-KarlsUniversity, Tübingen, Germany, 1991.

50 S. Lübke and H. D. Wiemhöfer, Solid State Ionics, 1999, 117, 229-243.

51 K. Schmale, M. Grünebaum, M. Janssen, S. Baumann, F. Schulze-Küppers and H.-D. Wiemhöfer, Phys. Status Solidi $B, 2011,248,314-322$.

52 K. Teske, H. Ullmann and N. Trofimenko, J. Therm. Anal. Calorim., 1997, 49, 1211-1220.

53 N. Sakai, T. Hashimoto, T. Katsube, K. Yamaji, H. Negishi, T. Horita, H. Yokokawa, Y. P. Xiong, M. Nakagawa and Y. Takahashi, Solid State Ionics, 2001, 143, 151-160.

54 R. D. Shannon, Acta Crystallogr., Sect. A: Cryst. Phys., Diffr., Theor. Gen. Crystallogr., 1976, 32, 751-767. 
55 C. Déportes, G. Robert and M. Forestier, Electrochim. Acta, 1971, 16, 1003-1023.

56 E. R. Andrievskaya, A. V. Samelyuk and L. M. Lopato, Powder Metall. Met. Ceram., 2002, 41, 63-71.

57 N. M. Sammes, G. A. Tompsett and Z. Cai, Solid State Ionics, 1999, 121, 121-125.

58 Y. Hinatsu and T. Muromura, Mater. Res. Bull., 1986, 21, 1343-1349.

59 V. G. Keramidas and W. B. White, J. Chem. Phys., 1973, 59, 1561.

60 W. H. Weber, K. C. Hass and J. R. McBride, Phys. Rev. B: Condens. Matter Mater. Phys., 1993, 48, 178-185.

61 A. Nakajima, A. Yoshihara and M. Ishigame, Phys. Rev. B: Condens. Matter Mater. Phys., 1994, 50, 13297-13307.

62 A. Banerji, V. Grover, V. Sathe, S. K. Deb and A. K. Tyagi, Solid State Commun., 2009, 149, 1689-1692.

63 A. Feinberg and C. H. Perry, J. Phys. Chem. Solids, 1981, 42, 513-518.

64 M. Ishigame and E. Yoshida, Solid State Ionics, 1987, 23, 211-218.

65 M. Yashima, H. Arashi, M. Kakihana and M. Yoshimura, J. Am. Ceram. Soc., 1994, 77, 1067-1071.

66 D.-J. Kim, H.-J. Jung and I.-S. Yang, J. Am. Ceram. Soc., 1993, 76, 2106-2108.

67 J.-P. Eufinger, Master thesis, JLU Gießen, Germany, 2010.

68 H. Schmalzried, Z. Phys. Chem., 1977, 105, 47.

69 D. W. Strickler and W. G. Carlson, J. Am. Ceram. Soc., 1964, 47, 122-127.

70 M. Martin, J. Electroceram., 2006, 17, 765-773.

71 J. C. Dyre, P. Maass, B. Roling and D. L. Sidebottom, Rep. Prog. Phys., 2009, 72, 046501.

72 H. Y. Xiao and W. J. Weber, J. Phys. Chem. B, 2011, 115, 6524-6533.

73 K.-I. Kawamura, K. Watanabe, Y. Nigara, A. Kaimai, T. Kawada and J. Mizusaki, J. Electrochem. Soc., 1998, 145, 2552-2558.

74 S. P. S. Badwal, Solid State Ionics, 1992, 52, 23-32.

75 D. Y. Wang, D. S. Park, J. Griffith and A. S. Nowick, Solid State Ionics, 1981, 2, 95-105.

76 B. O. H. Grope, T. Zacherle, M. Nakayama and M. Martin, Solid State Ionics, 2012, 225, 476-483.
77 L. Minervini, M. O. Zacate and R. W. Grimes, Solid State Ionics, 1999, 116, 339-349.

78 H. Naito, N. Sakai, T. Otake, H. Yugami and H. Yokokawa, Solid State Ionics, 2000, 135, 669-673.

79 H. L. Tuller and A. S. Nowick, J. Electrochem. Soc., 1975, 122, 255-259.

80 D. Schneider, M. Gödickemeier and L. J. Gauckler, J. Electroceram., 1997, 1, 165-172.

81 M. Mogensen, N. M. Sammes and G. A. Tompsett, Solid State Ionics, 2000, 129, 63-94.

82 S. Wang, H. Inaba, H. Tagawa, M. Dokiya and T. Hashimoto, Solid State Ionics, 1998, 107, 73-79.

83 P. Debye and E. Hückel, Phys. Z., 1923, 24, 305.

84 J. Janek, M. Martin and H. I. Yoo, Ber. Bunsen-Ges. Phys. Chem., 1994, 98, 655-664.

85 J. Janek and M. Martin, Ber. Bunsen-Ges. Phys. Chem., 1994, 98, 665-673.

86 A. R. Allnatt and M. H. Cohen, J. Chem. Phys., 1964, 40, 1860-1870.

87 A. R. Allnatt and P. C. Hoines, J. Chem. Phys., 1967, 46, 1154-1155.

88 R. A. Sevenich and K. L. Kliewer, J. Chem. Phys., 1968, 48, 3045-3066.

89 N. Hainovsky and J. Maier, Phys. Rev. B: Condens. Matter Mater. Phys., 1995, 51, 15789-15797.

90 J. Maier, Festkörper-Fehler und Funktion, Teubner, 2000.

91 N. H. March and M. P. Tosi, J. Phys. Chem. Solids, 1985, 46, 757-760.

92 P. Hartmann, T. Brezesinski, J. Sann, A. Lotnyk, J.-P. Eufinger, L. Kienle and J. Janek, ACS Nano, 2013, 7, 2999-3013.

93 S. Abdollahzadeh-Ghom, C. Zamani, T. Andreu, M. Epifani and J. R. Morante, Appl. Catal., B, 2011, 108-109, 32-38.

94 S. R. Bishop, T. S. Stefanik and H. L. Tuller, Phys. Chem. Chem. Phys., 2011, 13, 10165-10173.

95 R. N. Blumenthal and R. J. Panlener, J. Phys. Chem. Solids, 1970, 31, 1190-1192.

96 Y. Xiong, K. Yamaji, N. Sakai, H. Negishi, T. Horita and H. Yokokawa, J. Electrochem. Soc., 2001, 148, E489. 